\title{
The Cell Cycle is a Limit Cycle
}

\author{
C. Gérard ${ }^{1,2}$, A. Goldbeter ${ }^{1}$ * \\ ${ }^{1}$ Unité de Chronobiologie théorique, Faculté des Sciences, Université Libre de Bruxelles (ULB) \\ Campus Plaine, CP 231, B-1050 Brussels, Belgium \\ ${ }^{2}$ On leave at the Department of Biochemistry, University of Oxford, Oxford, UK
}

\begin{abstract}
Progression along the successive phases of the mammalian cell cycle is driven by a network of cyclin-dependent kinases (Cdks). This network is regulated by a variety of negative and positive feedback loops. We previously proposed a detailed, 39-variable model for the Cdk network and showed that it is capable of temporal self-organization in the form of sustained oscillations, which correspond to the repetitive, transient, sequential activation of the cyclinCdk complexes that govern the successive phases of the cell cycle [Gérard and Goldbeter (2009) Proc Natl Acad Sci 106, 21643-8]. Here we compare the dynamical behavior of three models of different complexity for the Cdk network driving the mammalian cell cycle. The first is the detailed model that counts 39 variables and is based on Michaelis-Menten kinetics for the enzymatic steps. From this detailed model, we build a version based only on mass-action kinetics, which counts 80 variables. In this version we do not need to assume that enzymes are present in much smaller amounts that their substrates, which is not necessarily the case in the cell cycle. We show that these two versions of the model for the Cdk network yield similar results. In particular they predict sustained oscillations of the limit cycle type. We show that the model for the Cdk network can be reduced to a version containing only 5 variables, which is more amenable to stochastic simulations. This skeleton version retains the dynamic properties of the more complex versions of the model for the Cdk network in regard to Cdk oscillations. The regulatory wiring of the Cdk network therefore governs its dynamic behavior, regardless of the degree of molecular detail. We discuss the relative advantages of each version of the model, all of which support the view that the mammalian cell cycle behaves as a limit cycle oscillator.
\end{abstract}

Keywords and phrases: cell cycle, model, Cdk network, oscillations, cellular rhythm

Mathematics Subject Classification: 92C37

\section{Modeling the dynamics of the cell cycle}

The cell division process plays a major role in unicellular and pluricellular organisms. In the latter it underlies the development from fertilized eggs into mature organisms. Understanding the dynamical bases of the cell cycle is crucial not only in normal physiological conditions but also in pathological ones, because deregulation of the cell cycle underlies abnormal cell proliferation leading to cancer. Mathematical models of the cell cycle based on experimental observations are helpful in view of the considerable complexity of this major cellular regulatory network, whose dynamical behavior cannot be comprehended solely by

\footnotetext{
${ }^{*}$ Corresponding author. E-mail: agoldbet@ulb.ac.be
} 
means of sheer intuition. Here we introduce models for the regulatory network driving the cell cycle after briefly reviewing the main experimental observations on which they are based. These models suggest that the regulatory network that repetitively governs transitions between successive phases of the cell cycle behaves as a sustained oscillator of the limit cycle type.

Before turning to the mammalian system, experimental studies in frog embryos and yeast allowed to discover the main molecular regulatory mechanisms that drive progression in the cell cycle. The embryonic cell cycle is composed of two phases: interphase, where DNA replication occurs, and mitosis where cell divides into two daughter cells. The progression in the interphase is driven by the accumulation of a protein named cyclin [1]. At the transition between interphase and mitosis, the level reached by cyclin allows to activate a kinase, Cdc2 (also known as Cdk1), which forms with cyclin a complex called MPF (Mitosis Promoting Factor) [2]. During mitosis, MPF activates, by phosphorylation, the APC complex that promotes cyclin degradation [3]. The latter regulation creates a negative feedback loop, which might be capable of generating oscillations in the levels of cyclin and Cdk. Such oscillations would correspond to the repetitive passage of the cell through mitosis in the first embryonic cycles. Early on, theoretical models were proposed for the dynamics of the amphibian embryonic cell cycle $[4,5]$. Besides negative feedback, experimental as well as theoretical studies showed the importance of positive feedback (PF) loops in the activation of the kinase Cdc2 for the entry into mitosis [6-9]. These PF loops create hysteresis and a bistable switch in the activation of $\mathrm{Cdc} 2$, which promotes an all-or-none transition between interphase and mitosis. More complex models, in terms of number of variables, were also proposed to account for the dynamics of the yeast cell cycle [10-12]. By providing a comprehensive picture of the cell cycle in budding yeast, this model is able to reproduce the dynamical behavior of more than one hundred cell cycle mutants [11].

The situation for mammalian cells appears to be more complex. As in yeast, the cell cycle consists of four phases: G1, S (DNA replication), G2 and M (mitosis, or cell division). A network of cyclin-dependent kinases (Cdks) larger than in yeast drives the progression along the different phases of the mammalian cell cycle $[13,14]$. The huge complexity of this network stems from that it is controlled by multiple regulations, which ensure that each $\mathrm{Cdk}$ is activated in turn, in a transient manner. Thus, the activities of cyclin D/Cdk4-6 and cyclin E/Cdk2 promote progression in the G1 phase and elicit the G1/S transition, cyclin $\mathrm{A} / \mathrm{Cdk} 2$ ensures progression in $\mathrm{S}$ and $\mathrm{G} 2$, while the peak of activity of cyclin B/Cdk1 brings about the G2/M transition. The complexity of the molecular regulatory mechanisms of the Cdk network makes it necessary to resort to computational modeling to apprehend the dynamics of the cell cycle.

Models were initially proposed to account for the dynamics of parts of the mammalian cell cycle such as the G1/S transition [15-17], the restriction point that defines a point of no return beyond which the cell does not need the presence of growth factor to complete a cycle [18], or the exit of mitosis [19]. A detailed, 39 -variable model [20] as well as a 5-variable version derived from this model [21,22] were proposed for the dynamics of the full mammalian cell cycle. Models were subsequently proposed to account for the coupling between the mammalian cell cycle and the circadian clock [23,24]. This coupling appears to be important for cell cycle progression in healthy cells and might be altered in the case of cancer [25-27].

Here we compare the dynamical properties of three different models of increasing complexity for the Cdk network driving the mammalian cell cycle. The first model, which counts 39 variables, provides a detailed description of the Cdk network [20]. In this version the kinetics of the various enzymatic steps is of the Michaelis-Menten type, i.e., based on the assumption that enzymes are present in much smaller amounts than their substrates. However, because the substrates are often proteins modified by enzymes, and themselves enzymes acting on other protein substrates, such an assumption may be questioned. Indeed, the levels of enzyme and substrate may be of similar magnitude, as may happen for kinases and phosphatases which play major regulatory roles in the cell cycle. In such a case it is more appropriate to resort to mass-action kinetics, which does not involve the assumption of concentration differences between enzymes and their substrates. Relaxing the Michaelis-Menten hypothesis of quasi-steady state for the enzyme-substrate complexes leads to an increase in the number of variables. Based on the detailed 39variable model for the Cdk network, we propose here a version of this model based only on mass-action 
kinetics, which counts 80 variables. Both versions of the model give largely similar results in regard to their capability of generating sustained oscillations. This supports the use of the Michaelis-Menten approximation in the model for the Cdk network, although other forms could be used for approximating the kinetics of enzymes in the limit where the enzyme concentration becomes of the same order as that of the substrate [28-30].

The versions of the model for the Cdk network containing 80 or 39 variables can be significantly reduced if one is ready to relinquish a number of biochemical details and some aspects of Cdk regulation, while attempting to retain the core regulatory structure of the Cdk network. A reduction of the detailed model based on the same global regulatory structure but counting only 5 variables has been proposed as a backbone of the 39-variable model $[21,22]$. This skeleton model reproduces many aspects of dynamic behavior of the more complex versions of the model for the Cdk network. In particular, it also produces limit cycle oscillations. We conclude by discussing the relative merits of each of the three versions of the model, which all support the view that the mammalian cell cycle operates as a limit cycle oscillator.

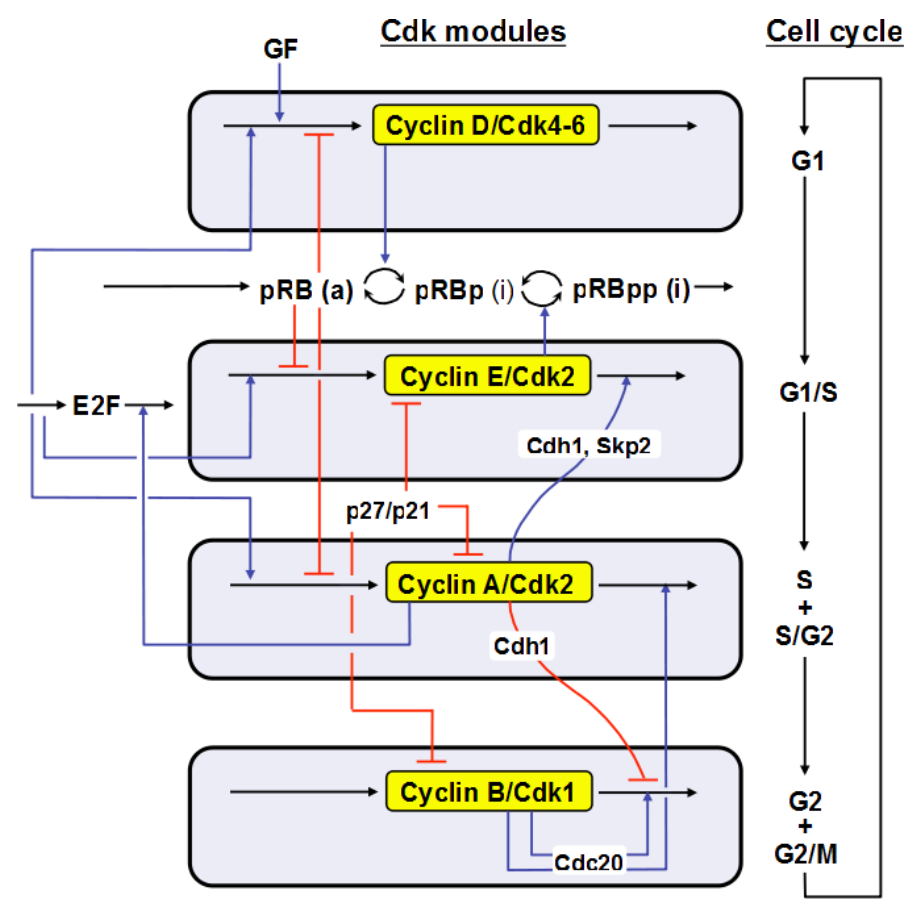

FiguRE 1. Scheme of the model for the Cdk network driving the mammalian cell cycle. The model is based on four modules, each centered on a different cyclin/Cdk complex. Cyclin D/Cdk4-6 and cyclin E/Cdk2 drive progression in G1 and trigger the G1/S transition, respectively. Cyclin A/Cdk2 permits progression in S and G2, while cyclin B/Cdk1 brings about the G2/M transition. Also indicated are the effect of growth factor (GF), the role of $\mathrm{pRB}$ and $\mathrm{E} 2 \mathrm{~F}$, which respectively promote and impede progression in the cell cycle, and the effect of the Cdk inhibitor p27/p21. The growth factor GF induces the G0/G1 transition and entry into the cell cycle by promoting the synthesis of cyclin D. The tumor suppressor pRB represses cyclins synthesis, while the transcription factor E2F activates it; p27/p21 can bind to the various cyclin/Cdk complexes, inhibiting their activity. More details of the regulatory interactions of the cyclin/Cdk network driving the mammalian cell cycle are described in [20]. 

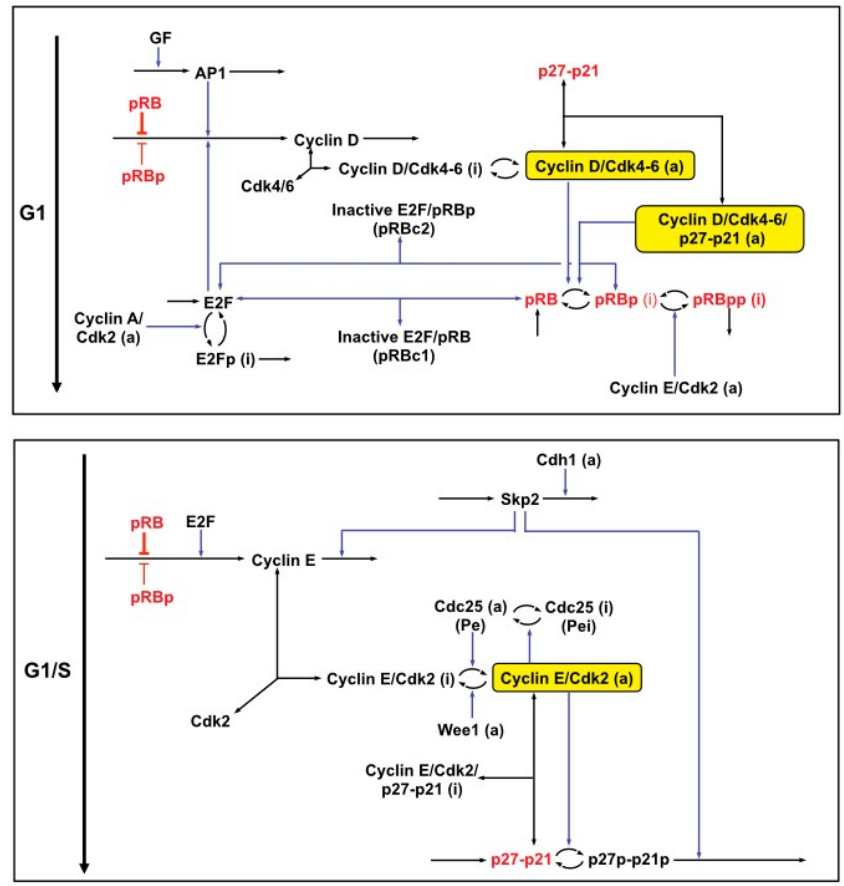

Figure 2. Detailed description of the first two modules in the 39-variable model for the Cdk network driving the mammalian cell cycle [20]. (Upper panel) Scheme of the cyclin D/Cdk4-6 module driving progression in G1. The growth factor (GF) activates the synthesis of the transcription factor AP1, which promotes synthesis of cyclin D. This cyclin reversibly forms a complex with the cyclin-dependent kinase Cdk4-6. The active form of cyclin D/Cdk4-6 can also form a complex with the Cdk inhibitor p27/p21, but this binding does not result in the inhibition of cyclin $\mathrm{D} / \mathrm{Cdk} 4-6$, contrary to what is observed for Cdk1 and Cdk2 (see Supporting Information in [20]). Cyclin D/Cdk4-6 promotes the phosphorylation and inactivation of $\mathrm{pRB}$. This phosphorylation allows the activation of E2F. The non-phosphorylated and mono-phosphorylated forms of $\mathrm{pRB}$ can attach to E2F, and thereby inhibit its transcriptional activity. A second phosphorylation of $\mathrm{pRB}$ by cyclin E/Cdk2 totally inhibits pRB, as the twice-phosphorylated form of pRB cannot bind to E2F. This second phosphorylation thus fully activates E2F. (Bottom panel) Scheme of the cyclin E/Cdk2 module controlling the G1/S transition. The synthesis of cyclin $\mathrm{E}$ is induced by $\mathrm{E} 2 \mathrm{~F}$, and inhibited by $\mathrm{pRB}$ and $\mathrm{pRBp}$, both directly and indirectly through formation of inactive complexes between $\mathrm{pRB}$ and $\mathrm{pRBp}$ with E2F. Cyclin E reversibly forms a complex with Cdk2. The activity of this complex is regulated by phosphorylation-dephosphorylation: the phosphatase Cdc25 activates the cyclin E/Cdk2 complex by dephosphorylating Cdk2, while the kinase Wee1 inactivates it by phosphorylation. A positive feedback (PF) loop exists between cyclin E/Cdk2 and its $\mathrm{Cdc} 25$ phosphatase (Pe): cyclin E/Cdk2 activates Cdc25 by phosphorylation, while Cdc25 activates cyclin E/Cdk2. Cyclin E/Cdk2 can also be regulated by reversible formation of a complex with p21-p27. The accumulation of cyclin E/Cdk2 leads to phosphorylation of its inhibitor $\mathrm{p} 21 / \mathrm{p} 27$. This phosphorylation brings about the specific degradation of $\mathrm{p} 21 / \mathrm{p} 27$, under control by the Skp2 protein, which belongs to the proteasome. Skp2 also controls the degradation of cyclin E, which ensures that the activity of cyclin E/Cdk2 decreases at this phase of the cycle. 

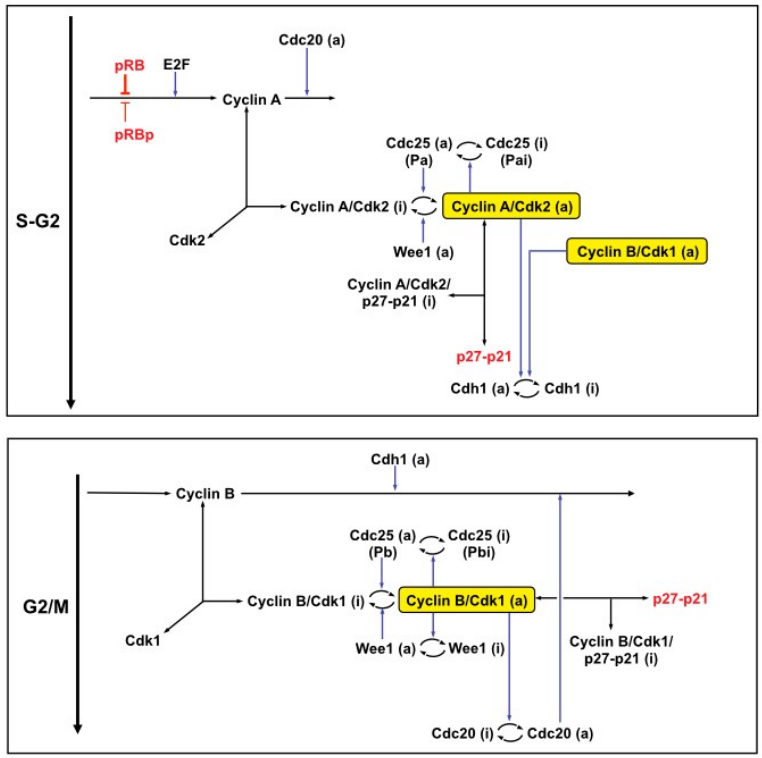

Figure 3. Detailed description of the last two modules in the 39-variable model for the Cdk network driving the mammalian cell cycle [20]. (Upper panel) Scheme of the cyclin A/Cdk2 module controlling the S-G2 transition. The synthesis of cyclin A is induced by E2F, and inhibited by pRB and pRBp. Like cyclin E, cyclin A can reversibly form a complex with Cdk2. A phosphatase Cdc25 activates by dephosphorylation cyclin A/Cdk2, while the kinase Wee1 inactivates it by phosphorylation. A PF loop exists between cyclin $\mathrm{A} / \mathrm{Cdk} 2$ and its phosphatase $\mathrm{Cdc} 25(\mathrm{~Pa})$. Indeed, Cdc25 activates cyclin $\mathrm{A} / \mathrm{Cdk} 2$, and cyclin A/Cdk2 activates Cdc25 by phosphorylation. Cyclin A/Cdk2 can also be regulated by reversible formation of a complex with $\mathrm{p} 21 / \mathrm{p} 27$. The cyclin A/Cdk2 complex controls the S/G2 transition by promoting the phosphorylation and subsequent degradation of E2F. Cyclin A/Cdk2 and cyclin B/Cdk1 both phosphorylate and thereby inhibit the protein Cdh1. This inhibition leads to the accumulation of cyclin B and to the G2/M transition. (Bottom panel) Scheme of the cyclin B/Cdk1 module controlling the G2/M transition. In the preceding module (see upper panel), cyclin A/Cdk2 inhibits by phosphorylation the protein Cdh1. This protein cannot promote the degradation of cyclin B anymore, which increases the level of cyclin B. Cyclin B reversibly forms a complex with Cdk1. Cyclin B/Cdk1 also phosphorylates and inhibits Cdh1; this results in mutual inhibition between $\mathrm{Cdk} 1$ and Cdh1, creating another PF loop. The activity of cyclin B/Cdk1 can also be regulated by phosphorylation-dephosphorylation. A phosphatase $\mathrm{Cdc} 25(\mathrm{~Pb})$ activates cyclin $\mathrm{B} / \mathrm{Cdk} 1$ through dephosphorylation, while the kinase Wee1 inactivates it through phosphorylation. A PF loop is again present between cyclin B/Cdk1 and its Cdc25 phosphatase: Cdc25 activates cyclin B/Cdk1, while cyclin $\mathrm{B} / \mathrm{Cdk} 1$ activates Cdc25. A second PF loop involves cyclin B/Cdk1 and Wee1. Indeed, cyclin $\mathrm{B} / \mathrm{Cdk} 1$ inhibits, by phosphorylation, the kinase Wee1, while the latter phosphorylates and thereby inhibits cyclin B/Cdk1. The peak of activity of cyclin B/Cdk1 brings about the entry into mitosis. The rise in cyclin B/Cdk1 ensures the activation, by phosphorylation, of the protein Cdc20. This creates a negative feedback loop because Cdc20 allows the degradation of cyclin A and cyclin B, which decreases the activity of cyclin $\mathrm{A} / \mathrm{Cdk} 2$ and cyclin B/Cdk1 at the end of the cell cycle. Cells start a new cycle, corresponding to a new round of oscillations, in the presence of sufficient amounts of growth factor. 


\section{Detailed, 39-variable model for the mammalian cell cycle}

The detailed, 39-variable model for the mammalian cell cycle [20] is structured around four Cdk modules (see Fig. 1 for a simple, global scheme of the Cdk network and Figs. 2 and 3 for a detailed description of each of the four modules of the molecular regulatory network). Each module is centered on one cyclin/Cdk complex: cyclin D/Cdk4-6, cyclin E/Cdk2, cyclin A/Cdk2, and cyclin B/Cdk1. Activation of the cyclin D/Cdk4-6 module in the presence of growth factor (GF) promotes progression in G1, while the cyclin E/Cdk2 module allows the G1/S transition and elicits entry into DNA replication (Fig. 2). Cyclin A/Cdk2 ensures progression in $\mathrm{S}$ and the $\mathrm{S} / \mathrm{G} 2$ transition, while cyclin $\mathrm{B} / \mathrm{Cdk} 1$ brings about the G2/M transition (Fig. 3). Once activated, cyclin B/Cdk1 promotes the activation, by phosphorylation, of the protein Cdc20 that belongs to the proteasome [31,32]. This latter protein is responsible for the degradation of cyclins A and B, which creates negative feedback loops in the activity of these cyclin/Cdk complexes and allows cells to complete the cell cycle.

During the cell cycle, the activity of cyclin/Cdk complexes is regulated by phosphorylationdephosphorylation: phosphatases Cdc25 activate the Cdks by dephosphorylation, while the kinase Wee1 inhibits their activity by phosphorylation [13]. In their turn, cyclin E/Cdk2, cyclin A/Cdk2, and cyclin B/Cdk1 can activate, by phosphorylation, their corresponding phosphatase Cdc25, which creates positive feedback loops [33]. Cyclin B/Cdk1 can also inhibit, by phosphorylation, the kinase Wee1; this generates mutual inhibition between Wee1 and cyclin B/Cdk1, and thus creates another positive feedback loop. The reversible association with the inhibitor p21-p27 can also regulate the activity of the various cyclin/Cdk complexes. In the model, the synthesis of cyclins $\mathrm{D}, \mathrm{E}$, and $\mathrm{A}$ is activated by the transcription factor E2F and repressed by the tumor suppressor pRB. In their turn, the cyclin/Cdk complexes can regulate the activity of the $\mathrm{E} 2 \mathrm{~F} / \mathrm{pRB}$ pathway by phosphorylation. The phosphorylated forms of $\mathrm{pRB}$ are inhibited and cannot repress anymore the transcriptional activity of E2F; this results in the activation of E2F and favors progression in the cell cycle; see Fig. 1, as well as Figs. 2 and 3, for further details on the regulatory mechanisms of the Cdk network controlling the mammalian cell cycle. We shall recall the salient dynamical properties of the 39 -variable model for the mammalian cell cycle after presenting the 80-variable version based on this model, so as to compare the predictions of the two versions. In particular, we will study the effect of the presence of growth factor on the dynamics of the Cdk network. We will also illustrate the antagonistic effects of the tumor suppressor pRB and the transcription factor E2F on the control of cell cycle progression.

\section{A model for the mammalian cell cycle based on mass-action kinetics}

From the detailed, 39-variable, model proposed for the dynamics of the Cdk network driving cell cycle progression [20], we present here a version of this model based on mass-action kinetics. This version takes explicitly into account the formation of complexes between enzymes and substrates and does not rest on the simplifying quasi-steady state assumption leading to the Michaelis-Menten rate laws. It is however much more complex as it contains 80 variables instead of 39 in the original version based on Michaelis-Menten kinetics [20].

The Michaelis-Menten kinetics rests on the assumption that the substrate concentration is much larger than the concentration of the enzyme. In the case of the cell cycle this assumption is not always verified. Indeed, the concentration of substrate and enzyme can be of the same order of magnitude. A protein in the Cdk network can be, at the same time, an enzyme and a substrate for another protein. For example, the kinase Wee1 inhibits, by phosphorylation, the complex cyclin B/Cdk1, while the latter complex also inhibits, by phosphorylation, the kinase Wee1.

Previous studies pointed out that a Michaelis-Menten rate law is not valid in protein interaction networks where concentrations of enzyme and substrate are comparable or if the Michaelis contant is not much larger than the concentration of enzyme and substrate respectively [29,30,34]. In particular, based on the classical Michaelis-Menten approximation, a total quasi-steady state approximation (tQSSA), which 

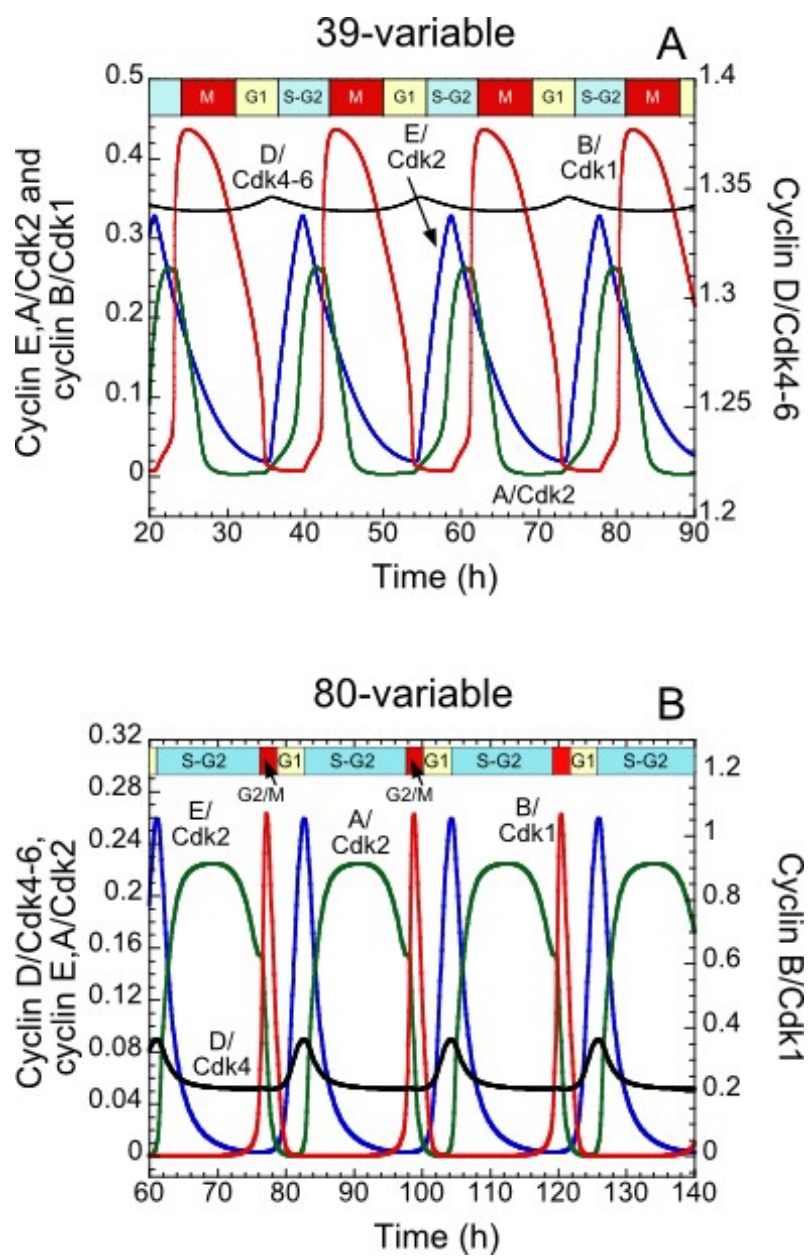

FiguRE 4. Sustained oscillations in the Cdk network in presence of a suprathreshold level of growth factor. The curves show the time evolution of cyclin D/Cdk4-6, cyclin E/Cdk2, cyclin $\mathrm{A} / \mathrm{Cdk} 2$, and cyclin $\mathrm{B} / \mathrm{Cdk} 1$ in the 39 -variable (A) and 80-variable (B) versions of the model. The transient and ordered activation of the various cyclin/Cdk complexes ensures the correct progression along the successive phases of the cell cycle. In both cases, the level of cyclin D/Cdk4-6 remains more or less constant in the course of time. The peak of activity of cyclin E/Cdk2 controls the G1/S transition. The rise in cyclin A/Cdk2 promotes progression in $\mathrm{S}$ and $\mathrm{G} 2$, while the peak in the activity of cyclin B/Cdk1 elicits the $\mathrm{G} 2 / \mathrm{M}$ transition. In both panels, the duration of the cell cycle is about $20 \mathrm{~h}$, but the relative duration of the different phases differs (see text). The relative duration of the cell cycle phases depends on the parameter values considered, which are not necessarily the same in the two versions of the model. For the 39-variable version of the model for the Cdk network, parameter values are as in Table S2 in Supporting Informations in [20], while for the 80-variable version, the kinetic equations and parameter values are listed in Appendix, in section 2 and in Table 3, respectively.

extends the limit of validity of the Michaelis-Menten kinetics was proposed [29]. This tQSSA was used to study the dynamics of a phosphorylation-dephosphorylation switch [35] and to study the dynamics of two and three such switches coupled together, which can illustrate the dynamics of a molecular network governing cell cycle progression [30]. In the latter study, the authors showed that the tQSSA can faithfully 

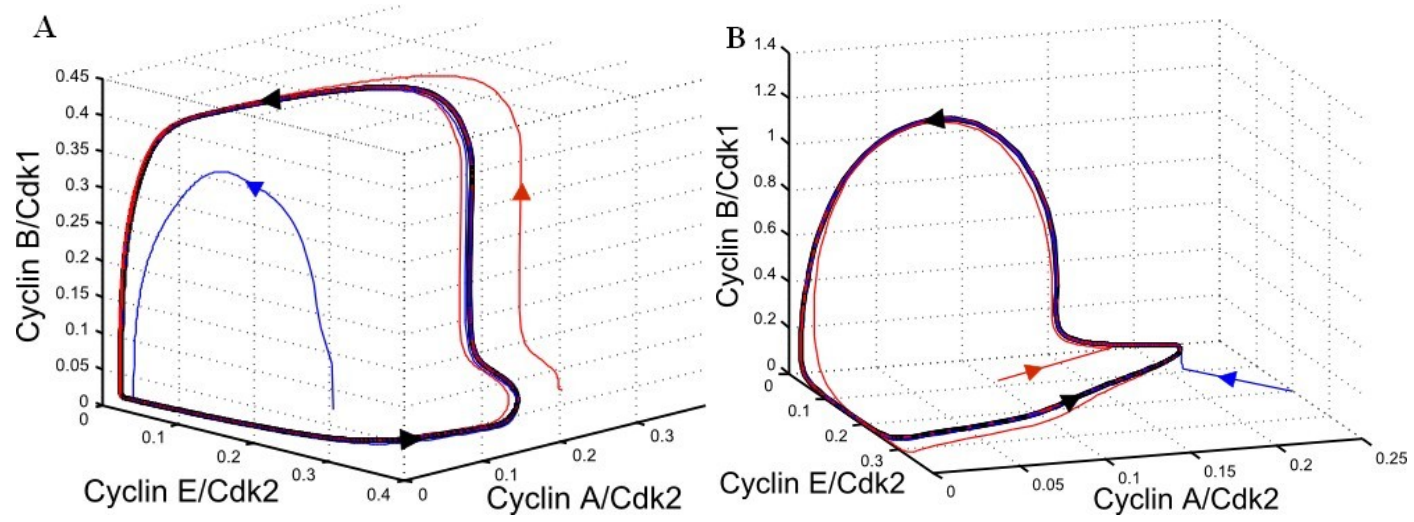

FiguRe 5. Limit cycle in the Cdk network. The curves represent the projection of the system's trajectory on the three-dimensional space defined by cyclin E/Cdk2, cyclin $\mathrm{A} / \mathrm{Cdk} 2$ and cyclin B/Cdk1 for the 39-variable $(\mathrm{A})$ and 80-variable (B) versions of the model for the Cdk network. The arrows indicate the direction of movement along the limit cycle. The curves correspond to the oscillations shown in Fig. 4.

reproduce the dynamics of the network both qualitatively and quantitatively. As originally proposed by Michaelis and Menten in their equilibrium approximation, the substrate is in instantaneous equilibrium with the enzyme/substrate complex. The equilibrium approximation is valid if the substrate reaches the equilibrium much faster than the product is formed. Thus, the rate of formation/dissociation of the complex must be high as compared to the rate of production of the product in order to validate the approximation.

In the general case, which covers all situations, i.e. in the absence of any simplifying assumption of the Michaelis-Menten or tQSSA type, the dynamics of the model for the Cdk network is governed by a set of 80 kinetic equations based on the mass-action law. These equations are given in section 2 in Appendix, where the variables are defined in Table 2 , while the definition of the parameters with their values used in numerical simulations are listed in Table 3.

\subsection{Oscillatory dynamics of the Cdk network driving the cell cycle}

In presence of sufficient amount of growth factor (GF), both in the 39-variable and 80-variable versions of the model, the Cdk network ceases to admit a stable steady state and evolves to a stable oscillatory regime. Figure 4 shows the dynamical behavior of the Cdk network in the presence of a suprathreshold amount of GF for the model containing 39 (Fig. 4A) or 80 variables (Fig. 4B). In both cases, the Cdk network undergoes sustained oscillations which can be associated with cell proliferation. The repetitive, ordered, transient activation of the various cyclin/Cdk complexes allows for correct progression along the successive phases of the cell cycle.

That the level of cyclin D/Cdk4-6 complex does not oscillate with large amplitude holds with the observation that the level of this complex remains more or less constant during the cell cycle [36]. The successive peaks of activity of cyclin $\mathrm{E} / \mathrm{Cdk} 2$, cyclin $\mathrm{A} / \mathrm{Cdk} 2$ and cyclin $\mathrm{B} / \mathrm{Cdk} 1$ respectively bring about the G1/S transition, the progression in $\mathrm{S}$ and the $\mathrm{S} / \mathrm{G} 2$ transition, and eventually the G2/M transition that completes the cell cycle. In the two versions of the model, parameter values were taken so that the period of the cell cycle is about $20 \mathrm{~h}$. The relative duration of the various phases of the cell cycle nevertheless differs in the two models. In particular the rise in cyclin E/Cdk2 and cyclin B/Cdk1 takes the form of spikes in the 80-variable model. The dissimilarity in waveform of the oscillations in the two versions of the model may be due to differences in the parameters values used for numerical simulations. Moreover, in the 39-variable model, the degradation of the various cyclin proteins is regulated by Michaelis-Menten kinetics, which can lead to enzyme saturation; this might cause a slower decrease in cyclin/Cdk complexes 

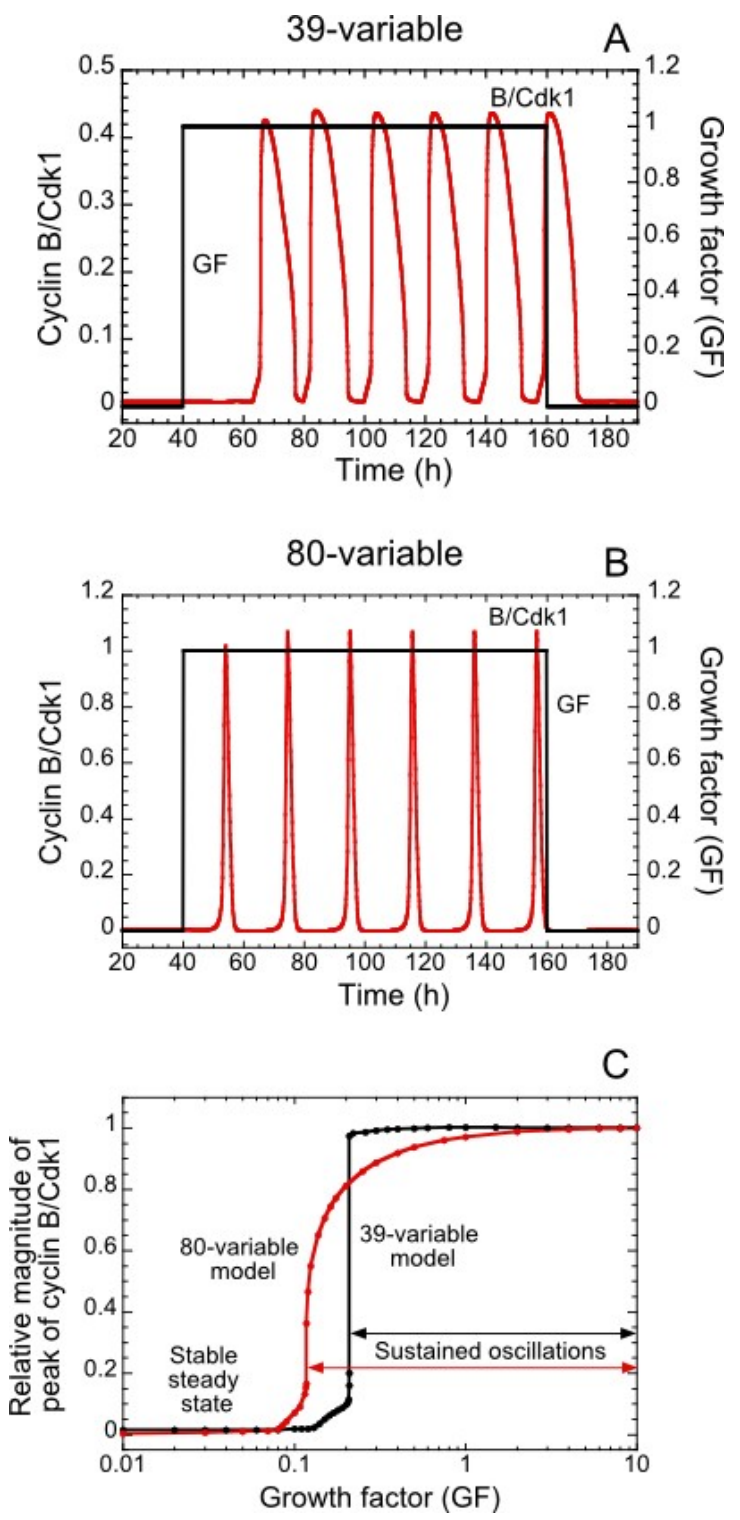

FiguRE 6. Effect of growth factor (GF) on the dynamics of the Cdk network. The curves in the upper two panels show the time evolution of cyclin B/Cdk1 in the absence of GF for $t<40 h$ and $t>160 \mathrm{~h}$, and in the presence of $\mathrm{GF}=1 \mu \mathrm{M}$ for $40<t<160 \mathrm{~h}$ in the 39-variable (A) and 80-variable (B) versions of the model. In both cases, in the absence of GF, the Cdk network tends to a stable steady state characterized by a low level of cyclin/Cdk complexes, which corresponds to a quiescent phase. In the presence of a suprathreshold amount of GF, the Cdk network undergoes sustained oscillations, which correspond to cell proliferation. (C) In both models, a threshold in the concentration of GF defines the transition between a stable steady state regime corresponding to cell quiescence and sustained oscillations corresponding to cell proliferation. Below and above the bifurcation value of GF, the points represent the steady-state level of cyclin B/Cdk1 or the maximum of the peak in cyclin B/Cdk1 during sustained oscillations, respectively. Parameter values are as in Fig. 4. 
as compared to the 80-variable model. Besides this difference in waveform, the two versions of the model account for the sequential activation of the various cyclin/Cdk complexes, needed for correct progression along the successive phases of the cell cycle.

For both versions of the model, sustained oscillations correspond to the evolution towards a stable limit cycle. The projection onto the (cyclin $\mathrm{E} / \mathrm{Cdk} 2$, cyclin $\mathrm{A} / \mathrm{Cdk} 2$, cyclin $\mathrm{B} / \mathrm{Cdk} 1$ ) space of the trajectory followed by the full system of equations is shown in Fig. 5 for the 39 -variable (A) and 80-variable (B) versions of the model. In each case the same, unique closed curve can be reached regardless of the initial conditions. This limit cycle behavior suggests that, in conditions of proliferation, the mammalian cell cycle can be viewed as an autonomous cellular rhythm corresponding to the temporal self-organization of the Cdk network $[20,37,38]$.

As a consequence of intertwined positive and negative feedback loops, which create multiple oscillatory circuits within the network, the 39-variable model for the mammalian cell cycle is also capable of generating complex modes of oscillatory behavior, such as complex periodic, quasi-periodic, as well as chaotic oscillations in the various cyclin/Cdk complexes [20,39]. However, numerical simulations based on a thorough, though limited, exploration in parameter space suggest that these complex modes of oscillatory behavior are less frequent than the evolution toward simple periodic behavior. This conclusion holds with the view that simple periodic oscillations correspond to the physiological dynamical behavior of the Cdk network [39].

\subsection{Effect of growth factor on the dynamics of the Cdk network}

Mammalian cells generally progress in the cell cycle only in the presence of sufficient amount of growth factor (GF). In absence of growth factor, cells remain in a stable steady state characterized by low levels of cyclin/Cdk complexes, which correspond to a quiescent phase. Figure 6 illustrates the effect of GF on the dynamics of the Cdk network. In both the 39-variable (A) and 80-variable (B) versions of the model, the Cdk network tends to a stable steady state in the absence of GF, whereas it reaches a sustained oscillatory regime in its presence. In both cases a sharp threshold defines the transition between the stable steady state and the sustained oscillatory domain, which corresponds to an abrupt transition between quiescence and proliferation (C). The curve is steeper in the 39-variable version of the model because the amplitude of Cdk1 oscillations reaches more rapidly a plateau as the level of GF increases. Besides this slight change in the form of the response curve, these results indicate that the effect of growth factor on the dynamics of the Cdk network is qualitatively similar in the 80-variable and 39-variable versions of the model for the Cdk network.

\subsection{Effects of pRB and E2F on the oscillatory dynamics of the Cdk network}

The transcription factor E2F and the tumor suppressor pRB are two important regulators of the mammalian cell cycle. E2F induces cell cycle progression, while pRB inhibits it, by activating or repressing cyclin synthesis, respectively (see Figs. 1-3). The balance between E2F and pRB is crucial for the control of progression in the cell cycle. If the level of $\mathrm{pRB}$ is too high, progression is prevented, while it is favored if the level of E2F becomes elevated [40,41]. The antagonistic effects of pRB and E2F are illustrated in Fig. 7 by plotting the time evolution of cyclin B/Cdk1 at different levels of pRB and E2F in the 39-variable (A) and 80-variable (B) versions of the model. From $t=0$ on, the levels of pRB and $\mathrm{E} 2 \mathrm{~F}$ allow cell cycling characterized by the repetitive activation of cyclin $\mathrm{B} / \mathrm{Cdk} 1$. In $\mathrm{t}=160 \mathrm{~h}$ a step increase in the level of $\mathrm{pRB}$ inhibits cell cycle progression: cyclin B/Cdk1 tends to a low steady-state level associated with cell cycle arrest. In $t=240 \mathrm{~h}$, a step increase in the level of E2F restores the repetitive activation of cyclin B/Cdk1, which permits to resume cell proliferation. A second increase in the level of pRB suppresses cell cycling and a further increase in the level of E2F elicits its resumption. This result indicates that the balance between $\mathrm{pRB}$ and $\mathrm{E} 2 \mathrm{~F}$ controls progression in the mammalian cell cycle in the 80 -variable as well as in the 39 -variable versions of the model.

The effects of $\mathrm{pRB}$ and GF on the dynamics of the cell cycle are very similar in the two versions of the model for the Cdk network. Indeed, in the presence of a high level of $\mathrm{pRB}$, cells need the presence of GF 

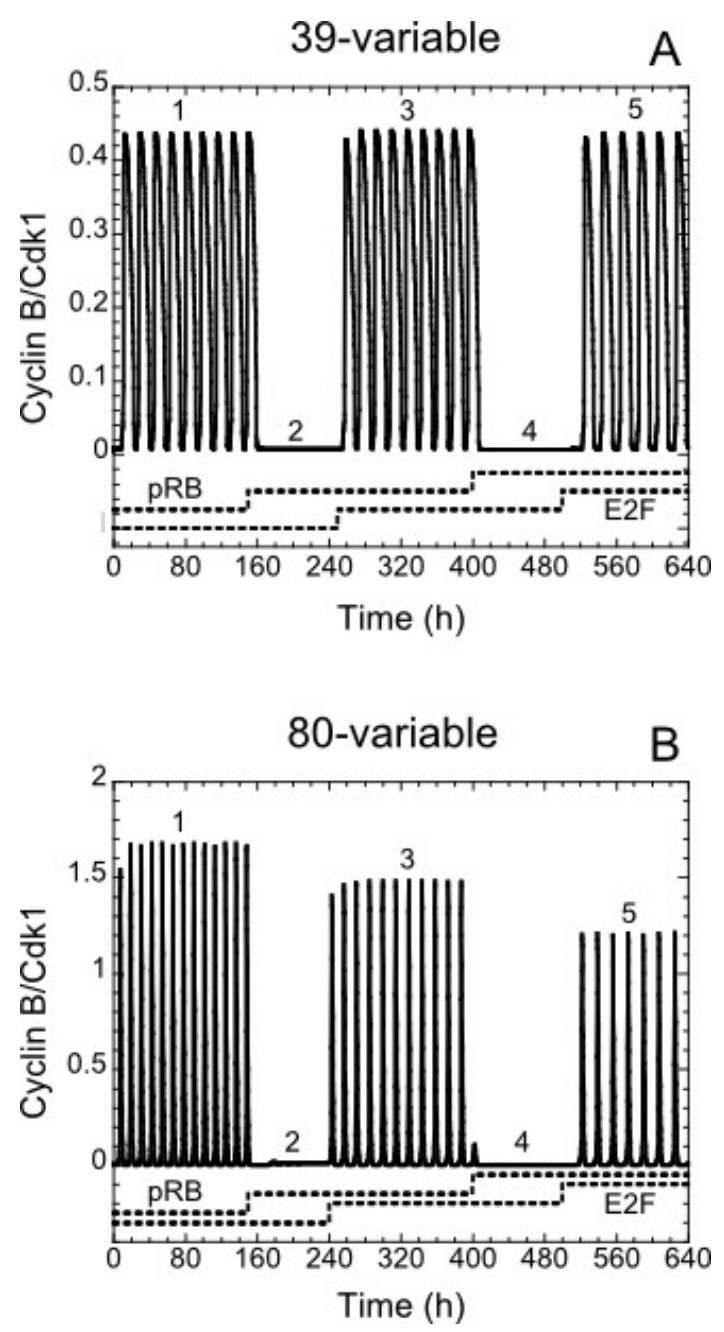

FiguRE 7 . The balance between the antagonistic effects of the tumor suppressor pRB and the transcription factor E2F controls cell cycle progression. The time evolution of cyclin B/Cdk1 illustrates the dynamical behavior of the Cdk network as a function of the rate of synthesis of $\mathrm{pRB}\left(\nu_{s p R B}\right)$ and the rate of synthesis of $\mathrm{E} 2 \mathrm{~F}\left(\nu_{s e 2 f}\right)$ for the 39-variable (A) and 80-variable (B) versions of the model. The Cdk network tends either to a stable steady state, corresponding to an arrest of the cell cycle, or to a sustained oscillatory regime, corresponding to cell proliferation. In both cases, a balance between $\mathrm{pRB}$ and E2F controls progression in the cell cycle as shown by changes in the rate of synthesis of E2F and pRB, $\nu_{s e 2 f}$ and $\nu s p R B$ (unit in $\mu M . h^{-1}$ ). Thus, increasing $\nu_{s p R B}$ from condition $1\left(\nu_{s p R B}=0.05, \nu_{s e 2 f}=0.01\right)$ in $(\mathrm{A})$ and $\left(\nu_{s p R B}=0.5, \nu_{s e 2 f}=0.04\right)$ in (B) to condition $2\left(\nu_{s p R B}=0.5, \nu_{s e 2 f}=0.01\right)$ in $(\mathrm{A})$ and $\left(\nu_{s p R B}=0.925, \nu_{s e 2 f}=\right.$ $0.04)$ in (B) suppresses cell cycle progression. From that condition, increasing $\nu_{s e 2 f}$ from condition 2 to $3\left(\nu_{s p R B}=0.5, \nu_{s e 2 f}=0.1\right)$ in $(\mathrm{A})$ and $\left(\nu_{s p R B}=0.925, \nu_{s e 2 f}=0.12\right)$ in (B) restores cell cycle progression. Again, further increasing $\nu_{s p R B}$ from condition 3 to $4\left(\nu_{s p R B}=5, \nu_{s e 2 f}=0.1\right)$ in $(\mathrm{A})$ and $\left(\nu_{s p R B}=1.525, \nu_{s e 2 f}=0.12\right)$ in (B) stops the oscillations. Finally, a last increase of $\nu_{s e 2 f}$ from condition 4 to $5\left(\nu_{s p R B}=5, \nu_{s e 2 f}=\right.$ $5)$ in $(\mathrm{A})$ and $\left(\nu_{s p R B}=1.525, \nu_{s e 2 f}=0.76\right)$ in (B) again restores the oscillations. Other parameter values are as in Fig. 4 . 
to enter the proliferation mode (Fig. 8A, C). When GF is removed, the Cdk network tends to a stable steady state, which corresponds to a non-proliferative state. However, in the presence of a reduced level of pRB, cells do not need the presence of GF to progress in the cell cycle (Fig. 8B, D). Even if GF is removed, the Cdk network undergoes sustained oscillations, which correspond to cell proliferation. This result accounts for the observation that cells become independent of GF to progress in the cell cycle when $\mathrm{pRB}$ is deleted $[42,43]$. The drop in the amplitude of Cdk1 oscillations in the 80-variable version of the model in the absence of GF is not seen in the 39-variable version. A difference in dependence of the amplitude on GF can also be discerned in the bifurcation diagram of Fig. 6C established as a function of the GF level.

\subsection{Effects of rate constants on the dynamics of the Cdk network}

Because the approximation of Michaelis-Menten kinetics becomes more valid at larger values of the Michaelis constants $[28,29]$, it is useful to determine in the 80 -variable model for the Cdk network the effect of the rate constants that characterize the dynamics of enzyme-substrate complexes and enter the definition of the Michaelis constant $K m$. For a given enzyme reaction the latter is defined as the ratio $(d+k) / a$, where $a$ and $d$ denote the association and dissociation rate constants for the formation of the enzyme-substrate complex, while $k$ denotes the catalytic constant measuring the rate at which the enzymesubstrate complex decomposes to yield the reaction product. We first multiplied parameters $a$ and $d$ by the same factor for all enzyme-substrate complexes in the 80 variable model. Sustained oscillations disappear when these constants decrease below a critical value, showing that fast kinetics for the formation and dissociation of the enzyme complexes favors the oscillations. In the initial derivation of their equation for enzyme kinetics, Michaelis and Menten assumed an instantaneous equilibrium for the enzyme/substrate complex. The equilibrium approximation requires that the rate of formation/dissociation of the complex must be high as compared to the rate of production of the product. The present numerical simulations of the Cdk network thus indicate that oscillations are favored in such conditions, which improve the validity of the Micahelis-Menten kinetics.

However, the range of validity of the Michaelis-Menten equation is wider [28,29]. It is thus useful to determine whether increasing the $K m$ favors the occurrence of oscillatory behavior, since this would further justify the use of Michaelian kinetics for enzymatic steps. When parameter $a$ is multiplied by the same factor for all enzyme-substrate complexes, which allows to modify the value of their $\mathrm{Km}$, simulations indicate that sustained oscillations occur in a range bounded by two critical values. Why do oscillations disappear when the $K m$ become too large? This is due to the fact that increasing the $K m$ for the enzymes involved in the degradation of the various cyclins tilts the balance between cyclin synthesis and degradation, since the synthesis terms are not affected by change in the $K m$ of the various enzymatic steps. Thus, oscillations disappear and the system evolves toward a stable steady state not because of an effect on the Michaelis constant per se but because of an alteration of the balance between cyclin synthesis and degradation. Oscillations only occur when this balance is maintained in an appropriate range. This result holds not only for the 80 -variable model but also for the 39 -variable version based on Michaelian kinetics (data not shown).

In the skeleton version of the model described below, oscillations occur in the Cdk network when the Michaelis constants are smaller than a critical value [22]. Small values of the Michaelis constants then favor oscillations because, in synergy with positive feedback loops, they increase the sensitivity of the switches that characterize the activation of Cdk2 and Cdk1 $[22,35]$.

\section{A skeleton, 5-variable version of the model for the Cdk network}

\subsection{Reducing the cell cycle model without and with Cdk regulation through phosphorylation-dephosphorylation}

From the detailed model, which counts 39 variables, or 80 variables in its most extended form based on mass-action kinetics, we have built a model that counts only 5 variables [21,22]. This model contains the 
four-cyclin/Cdk complexes that control progression along the different phases of the cell cycle. The 5variable model also contains the transcription factor $\mathrm{E} 2 \mathrm{~F}$, and the protein Cdc20 that permits to activate the degradation of cyclin A/Cdk2 and cyclin B/Cdk1 complexes (see Fig. 9). Cyclin D/Cdk4-6 is not coupled to the other variables of the model and rapidly reaches a stable steady state, so that it is not necessary to include it as a variable in the skeleton model.

To reduce the complexity of the model for the Cdk network has a price. We had to relinquish many biochemical details and also some of the variables present in the detailed model. Thus, the skeleton, 5 -variable model does not incorporate explicitly the formation of a complex between each cyclin and its corresponding Cdk. Instead we consider that cyclin/Cdk complexes are rapidly formed [21]. Moreover, the Cdk inhibitor p21-p27 is not present in the 5-variable model; this prevents the regulation of the activity of the four-cyclin/Cdk complexes through reversible association with this inhibitor. In contrast to the detailed model, to keep the number of variables low, the 5 -variable model does not take into account the tumor suppressor protein $\mathrm{pRB}$ in its various phosphorylated or nonphosphorylated forms. In the skeleton model, because we do not include the role of pRB, we assume that cyclin D/Cdk4-6 and cyclin E/Cdk2 directly activate E2F through phosphorylation. Moreover, we do not consider that E2F promotes the synthesis of cyclin A and cyclin E, leading to the activation of Cdk2, but rather assume, for simplicity, that the active form of E2F promotes the activation of Cdk2 through covalent modification; the total levels of the complexes involving Cdk2 and Cdk1 thus remain constant, while the total level of cyclin D/Cdk4-6 varies owing to its synthesis enhanced in the presence of the growth factor GF. These regulations are needed to reflect the regulatory structure present in the Cdk network, in which each Cdk module activates the next module and inhibits the preceding module(s) in the network.

In a first version of the skeleton model [21] we did not incorporate regulation of Cdk1 and Cdk2 through phosphorylation-dephosphorylation. To include this regulation, which allows for the self-amplification of Cdk activity, we recently extended the skeleton model by incorporating the regulation of Cdk2 and Cdk1 by the phosphatase Cdc25 and the kinase Wee1 [22] (see also Fig. 9). This extension of the model allows us to determine the effect of multiple positive feedback loops (represented by dashed arrows in the scheme of Fig. 9) on the dynamics of the cell cycle [22]. The kinetic equations of the extended version of the skeleton model for the Cdk network are given in section 1 of the Appendix, while the parameters are defined in Table 1, where their values used in the numerical simulations are also listed.

\subsection{Using the skeleton model to assess the effect of positive feedback on Cdk oscillations}

As in the detailed models for the mammalian cell cycle (see Fig. 4), the skeleton, 5-variable, model is also capable of temporal self-organization in the form of sustained oscillations in the presence of sufficient amount of growth factor $[21,22]$. The oscillations in the reduced model are shown in Fig. 10A. The corresponding limit cycle projected in the (cyclin $\mathrm{A} / \mathrm{Cdk} 2$, cyclin $\mathrm{E} / \mathrm{Cdk} 2$, cyclin $\mathrm{B} / \mathrm{Cdk} 1$ ) space is represented in Fig. 10B.

By resorting to this skeleton model we studied the role of positive feedback (PF) loops on the dynamics of the mammalian cell cycle [22]. In the latter model, the presence of PF loops promotes the occurrence of sustained oscillations of large amplitude in the various cyclin/Cdk complexes. Because the skeleton model contains only 5 variables, it is amenable to stochastic simulations, which allow us to assess the robustness of Cdk oscillations with respect to molecular noise. The results of stochastic simulations in the presence or absence of PF loops indicate that such feedback loops both increase the amplitude of Cdk oscillations and reinforce their robustness towards molecular noise [22]. This result corroborates and extends those from previous studies that show the crucial role of PF loops in promoting robust oscillations of the cyclin/Cdk network in the cell cycle $[44,45]$. 

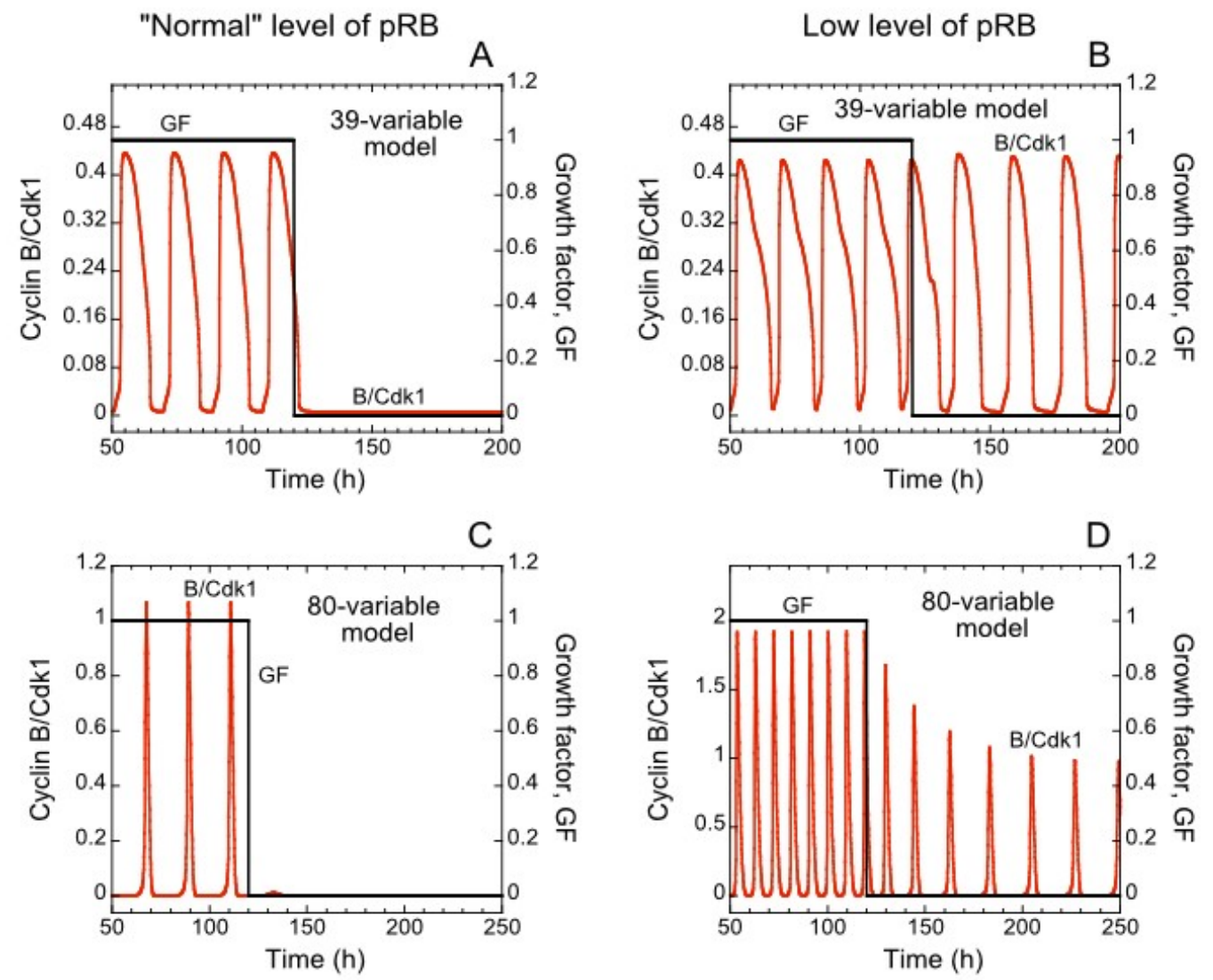

FiguRE 8. A decrease in the activity of pRB alters the growth factor dependence of the cell cycle. (A and C) In the presence of $\mathrm{pRB}$, when the rate of synthesis of $\mathrm{pRB}, \nu_{s p R B}$, is high and is equal to $1 \mu M h^{-1}$, the Cdk network needs the presence of GF to enter into an oscillatory domain corresponding to cell proliferation. (B and D) When the rate of synthesis of $\mathrm{pRB}, \nu_{s p R B}$, is reduced down to $0.5 \mu M h^{-1}$, the Cdk network does not depend on the presence of GF to undergo sustained oscillations. Other parameter values are as in Fig. 4.

\section{Discussion}

The mammalian cell cycle is driven by a network of cyclin-dependent kinases, which regulate the correct progression along the successive phases G1, S, G2, and M of the cell cycle [13,14]. Due to the complexity of this network, mathematical models are needed to fully apprehend the dynamics of the cell cycle. Models of varying degrees of complexity have been proposed for the cell cycle in amphibian embryos, yeast, and mammalian cells. In this study, we compared the properties of two versions of a detailed model for the Cdk network driving the mammalian cell cycle, which differ by the degree of complexity in the molecular description of the network. The first version contains 39 variables and provides a comprehensive description of the Cdk network [20]. To relax the hypothesis of Michaelis-Menten kinetics for the enzymatic steps that abound in the Cdk network we built a version of this model containing 80 variables, based only on mass-action kinetics. Finally we showed that the complexity of the model for the Cdk network can be largely reduced by considering a skeleton, 5 -variable model for the mammalian 


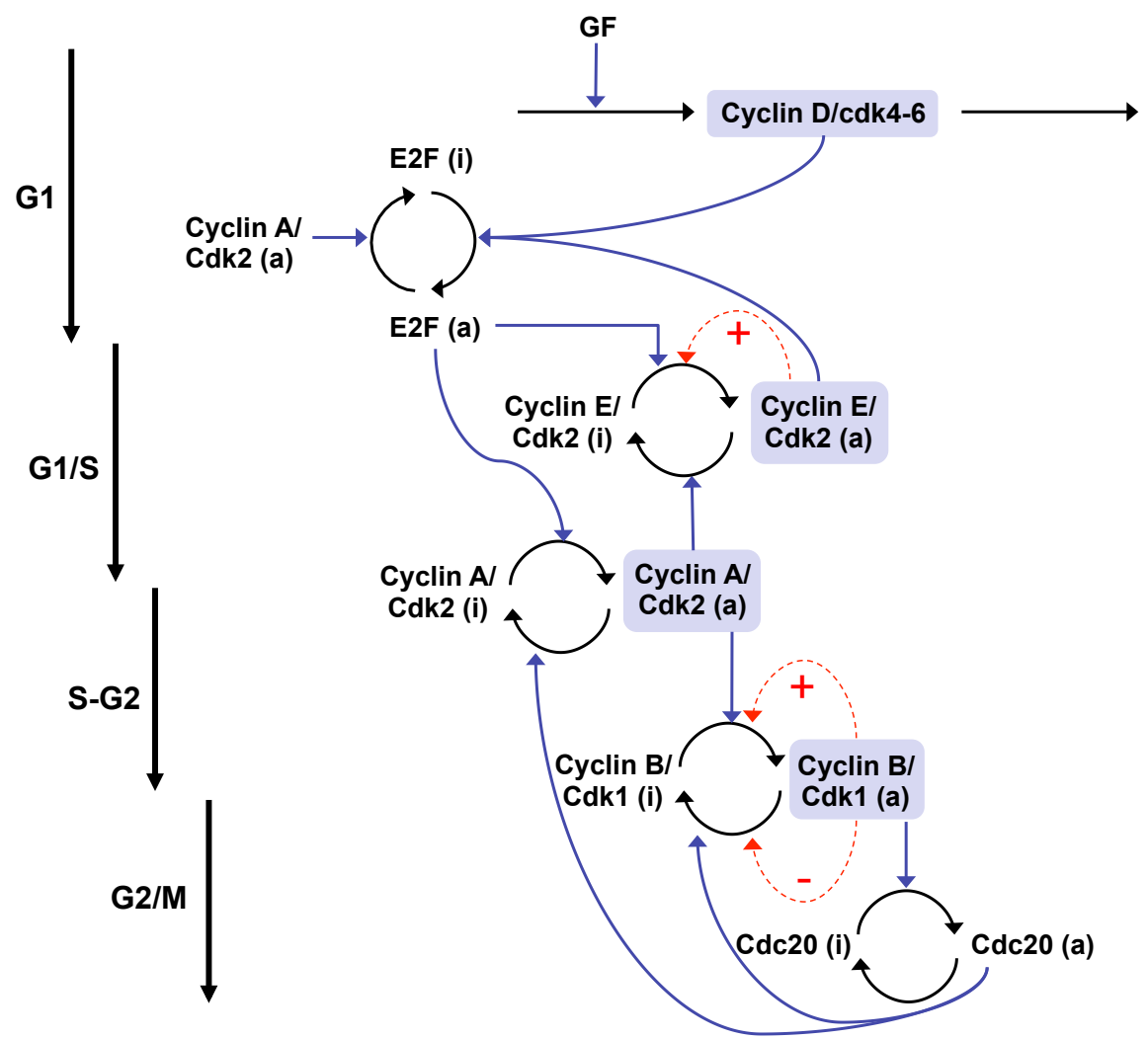

FiguRE 9. Scheme of the extended skeleton model for the mammalian cell cycle [22]. The model contains the four main cyclin/Cdk complexes, the transcription factor E2F, and the protein Cdc20. The progression in each phase of the cycle is controlled by one cyclin/Cdk complex: cyclin D/Cdk4-6 and cyclin E/Cdk2 drive progression in G1 and promote the G1/S transition; cyclin $\mathrm{A} / \mathrm{Cdk} 2$ ensures progression in $\mathrm{S}$ and $\mathrm{G} 2$, while cyclin B/Cdk1 elicits the G2/M transition. As in the detailed model (see Fig. 1), the presence of growth factor (GF) induces the entry in G1 by promoting the synthesis of cyclin D/Cdk4-6. This complex allows the activation of E2F, which will elicit the activation of cyclin E/Cdk2 at the G1/S transition, and that of cyclin A/Cdk2 during the $\mathrm{S}$ phase of DNA replication. During G2, cyclin A/Cdk2 also activates the synthesis of cyclin B/Cdk1, which triggers the peak of activity of cyclin B/Cdk1 at the G2/M transition. During mitosis, cyclin $\mathrm{B} / \mathrm{Cdk} 1$ activates by phosphorylation the protein Cdc20. This creates a negative feedback loop in the activity of cyclin A/Cdk2 and cyclin $\mathrm{B} / \mathrm{Cdk} 1$ by promoting the degradation of these two complexes. The regulations exerted by Cdc20 allow the cell to complete mitosis, and to start a new cycle if the growth factor is present in sufficient amount. Positive feedback loops can be added to the regulation of cyclin $\mathrm{E} / \mathrm{Cdk} 2$ and cyclin $\mathrm{B} / \mathrm{Cdk} 1$, which control the $\mathrm{G} 1 / \mathrm{S}$ and $\mathrm{G} 2 / \mathrm{M}$ transitions (dashed arrows in red). These positive feedback loops are due to the mutual activation between Cdk2, Cdk1 and their phosphatase Cdc25, and to the mutual inhibition between Cdk1 and the kinase Wee1. 

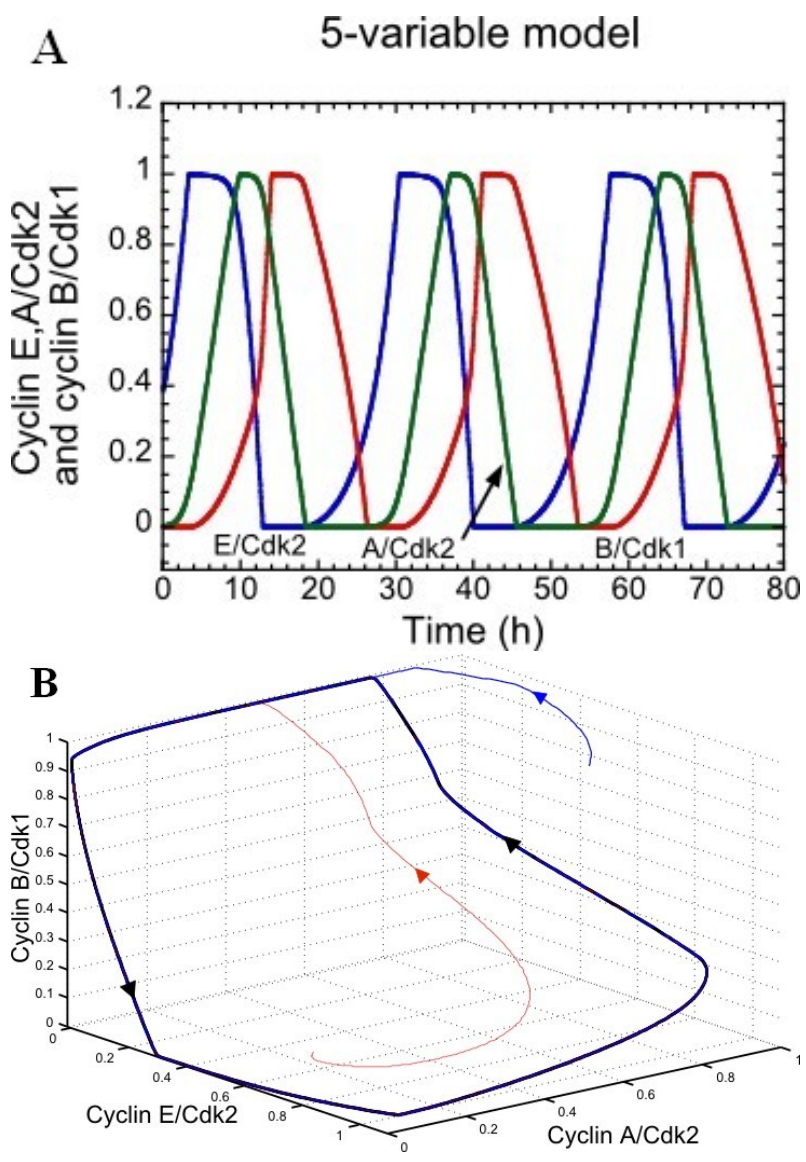

FiguRE 10. Sustained oscillations in the skeleton, 5-variable model for the Cdk network driving the mammalian cell cycle. The curves show the time evolution of cyclin E/Cdk2, cyclin A/Cdk2 and cyclin B/Cdk1 (A) as well as the projection of the corresponding limit cycle in a three-dimensional space (B). The 5 kinetic equations (see Appendix, section 1) are integrated numerically for the parameter values listed in Table 1 in Appendix, in the presence of the three positive feedback loops shown as dashed arrows in the scheme in Fig. 9.

cell cycle $[21,22]$.

The three models considered for the cell cycle exhibit similar dynamical properties. Indeed, in all cases, in the presence of sufficient amount of growth factor, the Cdk network tends to a sustained oscillatory regime corresponding to active cell proliferation (see Figs. 4 and 10A). These sustained oscillations correspond to the evolution towards a limit cycle; the same closed curve is indeed reached regardless of initial conditions (see Figs. 5 and 10B). Sustained oscillations in the Cdk network ensure the transient, ordered, repetitive activation of the different cyclin/Cdk complexes that govern the successive phases of the cell cycle.

In the absence of growth factor, the Cdk network tends towards a stable steady state corresponding to cell cycle arrest [20] (see Fig. 6). All versions of the model considered here for the Cdk network driving the mammalian cell cycle display an abrupt threshold in the level of GF separating a stable steady-state regime, for low levels of GF, from a regime of sustained oscillatory behavior at higher levels of GF. We suggest that this threshold defines the transition between quiescence and proliferation [20,21] (see Fig. $6 \mathrm{C})$. 
The model shows that the balance between factors that promote or impede cell cycle progression play a key role in the dynamics of the mammalian cell cycle. These factors are exemplified, respectively, by the transcription factor E2F and the tumor suppressor pRB. Indeed, in the two versions of the model, containing 39 or 80 variables, a rise in the level of E2F triggers progression in the cell cycle, while a rise in the level of pRB promotes cell cycle arrest [20](see Fig. 7). Moreover, both versions of the model show that in the presence of sufficient levels of $\mathrm{pRB}$, sustained oscillations in the Cdk network depend on the presence of growth factor, while in the absence of $\mathrm{pRB}$, or in the presence of too low levels, the sustained oscillatory behavior of the network becomes independent of the presence of GF (see Fig. 8 and also Ref. [46]). This result fits with experimental observations showing that cells may begin to proliferate in the absence of growth factor upon deletion of $\mathrm{pRB}[42,43]$.

The detailed versions of the model for the Cdk network driving the mammalian cell cycle are useful to study the antagonistic effect between oncogenes such as E2F or a tumor suppressor such as pRB on cell cycle progression. These issues cannot be addressed in the skeleton, 5-variable, model for the mammalian cell cycle because it lacks many of the molecular actors and biochemical details contained in the detailed versions of the model for the Cdk network. However, the reduced 5-variable version contains much fewer variables and parameters and is therefore more convenient to analyze the effect exerted on the dynamics of the cell cycle by regulatory mechanisms such as positive feedback loops mediated through phosphorylation/dephosphorylation. Deterministic and stochastic simulations indicate [22] that PF loops are crucial to ensure robust oscillations of large amplitude in the various cyclin/Cdk complexes in the cell cycle, in agreement with experimental observations [44]. The skeleton model for the mammalian cell cycle might also be a good tool to analyze the dynamics of synchronization of cells in a cell population. It is worth mentioning that a stochastic automaton in which all biochemical details are abandoned provides an even simpler model for the cell cycle [47]. This automaton model is particularly suitable for studying the desynchronization of cells in a cell population, as well as the entrainment of the cell cycle by the circadian clock and the effect of periodic or constant profiles of anticancer drug administration [48].

The main results of this study are twofold. First, the fact that the two versions of the model based on mass-action kinetics or Michaelis-Menten kinetics similarly predict oscillations in the Cdk network indicate that the latter, less complex version of the detailed model provides a good approximation for studying the dynamical properties of the Cdk network. Second, the observation of similar oscillations in a reduced skeleton model supports the view that the regulatory wiring of the Cdk network rather than the detailed biochemical implementation of the regulatory interactions within the network governs its dynamical behavior. All three versions of the Cdk network, of varying degrees of complexity, point to the conclusion that the mammalian cell cycle is a limit cycle.

Because the cell division cycle is a periodic process, the question arises as to what the cell cycle could be if not a limit cycle? This issue goes back to a long-standing discussion regarding the nature of the cell cycle: is it driven by a clock or by a discontinuous, hourglass mechanism [49-52]? In the latter view, a mitogen factor would accumulate in the course of time until it reaches a threshold beyond which it triggers cell division, which resets the system. For the mammalian cell cycle, this view must be extended since a single threshold does not suffice. Indeed, a threshold must be exceeded at the end of each cell cycle phase to bring about the passage to the next phase, until mitosis occurs. The events underlying the dynamics of the cell cycle thus occur sequentially, one event bringing about the next one, like a series of dominoes fall one after the other. To ensure the repetitive nature of the whole process, each domino must recover its original standing position after a while. This sequence of events can be described by a series of rules encompassing a discontinuity, like in an integrate-and-fire model. In such a description, the dynamics are imposed by the choice of the rule rather than being generated by the system itself. This is not the case with the continuous description of the Cdk network by a system of ordinary differential equations. The present results support the view of Murray and Kirschner who beautifully showed in their work on the embryonic cell cycle that the two views of the cell cycle-dominoes versus clock- can in fact be reconciled.

It is useful to recall the differences between a clock, limit cycle mechanism and a discontinuous, integrate- 
and-fire mechanism. A major difference pertains to the discontinuous nature of the latter mechanism. Such a discontinuous description fits with volume changes but not with the continuous dynamics of the Cdk network. Even if the cell volume undergoes a discontinuous transition at cell division, we view this process as being driven by a continuous oscillator. Because the variables in the model are the concentrations of the various cyclins, Cdks and their complexes, these do not undergo discontinuous changes at cell division, given that the molecules partition in a roughly identical manner between the two daughther cells. Thus, the discontinuous halving of the cell volume can be regarded as a marker of the continuous biochemical oscillator that drives this process of cytokinesis. Here we focused on the dynamics of the Cdk network driving the cell division cycle. The limit cycle dynamics relies on the temporal self-organization of the Cdk network, rather than on imposed mathematical rules.

One of the most striking differences between the two types of mechanism might be difficult to demonstrate experimentally. It pertains to entrainment and subharmonic entrainment by external periodic forcing. Such forcing occurs for the mammalian cell cycle because of its coupling to the circadian clock [24]. For limit cycle oscillations, as predicted theoretically and demonstrated by in vitro experiments for the case of glycolytic oscillations in yeast, sustained oscillations can be brought to oscillate at a frequency equal to a fraction of the frequency of an external periodic input [53]. Thus the glycolytic oscillator can switch from a period of $400 \mathrm{~s}$ to a period of $320 \mathrm{~s}$ when entrained in yeast extracts by a sinusoidal substrate input of a period of $160 \mathrm{~s}$. The same period of $400 \mathrm{~s}$ can also switch to $360 \mathrm{~s}$ when the glycolytic oscillator is subjected to a sinusoidal substrate input of $120 \mathrm{~s}$ period. In the former case, the glycolytic oscillator entrains to twice the period of its input, while in the latter case it entrains to three times the forcing period. These observations of subharmonic entrainment to $1 / 2$ or $1 / 3$ of the forcing frequency demonstrated that the oscillations that occur in yeast glycolysis are of the limit cycle type. In the cell cycle, a model for the coupling between the Cdk network and the circadian clock similarly shows [24] that in a certain range of autonomous period and for appropriate coupling strengths the period of the cell cycle can switch to the period of the circadian input $(24 \mathrm{~h})$ or to the double of this period, i.e. $48 \mathrm{~h}$. Such a subharmonic entrainment predicted theoretically has not yet been demonstrated for the cell cycle, but it is in principle possible owing to the multiple coupling of the cell cycle to the circadian clock. Subharmonic entrainment provides a signature of the limit cycle nature of a biological oscillator.

Sustained oscillations necessarily occur around a steady state, which is generally unstable. They can also occur around a stable steady state, which is then separated from the stable limit cycle by an unstable periodic trajectory. The limit cycle mechanism therefore implies the existence of a stable or unstable singularity, the steady state. When it is unstable the steady state behaves as a phaseless point $[50,51,54]$; indeed, after a finely adjusted perturbation that brings the system back precisely to the steady state, the system returns to the limit cycle with a random phase. This is the reason why such perturbations may suppress the oscillations in a cell population for several cycles, when the steady state is unstable, or permanently if the steady state is stable [55]. Another property of the limit cycle is that near the bifurcation point, after a perturbation that brings the system in the vicinity of the unstable steady state, the system undergoes oscillations of increasing amplitude until it reaches asymptotically the stable limit cycle.

In the case of the mammalian cell cycle, the Cdk network is regulated in such a manner that each cyclin/Cdk module activates the next module(s) and inhibits the previous one(s), so that they follow each other in a spontaneous, repetitive manner. When the transitions possess an all-or-none nature, which can be due to ultrasensitivity, bistability, or both $[6-9,22]$, the distinction between the two views of the dynamics largely vanishes, as previously shown for an abstract network of cyclically organized phosphorylation-dephosphorylation switches [56], and also observed for the present detailed model for the Cdk network. Such a conclusion corroborates the view of Murray and Kirschner (1989) expressed by the title of their article [57]: "Dominoes and clocks: The union of two views of the cell cycle".

Besides the above-mentioned properties of a limit cycle mechanism that are not observed in an integrateand-fire mechanism, a most important aspect is that the model for the Cdk network provides a continuous mathematical description for the passage through successive thresholds that correspond to the sequential 
activation of the various cyclin-Cdk complexes. The limit cycle mechanism provides an explicit molecular basis for these sequential transitions and for their repetitive nature, without resorting to any externally imposed mathematical rules based on discontinuous transitions. It explains how each molecular step spontaneously follows the preceding until the last step brings the system back to the initial stage.

If one focuses on the variations of the cell volume, which varies discontinuously, the dynamics can be described phenomenologically by an integrate-and fire mechanism. Such an approach may be coupled to a molecular model for the control of Cdk activity, as done, for example, in a hybrid model for the yeast cell cycle, which is controlled by cell mass [11]. Rather than focusing on the variation of cell volume, we consider it as a marker of the cell cycle that is driven by changes in the concentrations of cyclin/Cdk complexes, which behave as continuous variables. Cell mass seems to play a relatively minor role in cell cycle progression in mammals as compared to yeast cells [58]. Changes in cell volume nevertheless occur in the course of cell growth. In a first approximation we did not incorporate such changes and focused on the dynamics of the Cdk network as it may occur in cell-free extracts. The results predict that sustained Cdk oscillations should occur in mammalian cell extracts as observed in extracts of frog embryos [3] for a few successive cycles.

Acknowledgements. One of the authors (A.G.) would like to thank James Yorke for a stimulating discussion. This work was supported by grant $\mathrm{n}^{\circ} 3.4607 .99$ from the Fonds de la Recherche Scientifique Médicale (F.R.S.M., Belgium), by the Belgian Federal Science Policy Office (IAP P6/25 "BioMaGNet": "Bioinformatics and ModelingFrom Genomes to Networks"), and by the F.R.S.-FNRS (Belgium) in conjunction with the ErasysBio+ project C5Sys, "Circadian and Cell Cycle Clock Systems in Cancer". C.G. is a postdoctoral fellow at the University of Oxford, supported by the Philippe Wiener - Maurice Anspach Foundation.

\section{References}

[1] A.W. Murray, M.W. Kirschner. Cyclin synthesis drives the early embryonic cell cycle. Nature 339 (1989), $275-280$.

[2] A. Murray, T. Hunt. The Cell Cycle: An Introduction. W.H. Freeman and Company (1993), New York.

[3] M.A. Félix, J.C. Labbé, M. Dorée, T. Hunt, E. Karsenti. Triggering of cyclin degradation in interphase extracts of amphibian eggs by cdc2 kinase. Nature 346 (1990), 379-382.

[4] J.J. Tyson. Modeling the cell division cycle: cdc2 and cyclin interactions. Proc. Natl. Acad. Sci. USA 88 (1991), 7328-7332.

[5] A. Goldbeter. A minimal cascade model for the mitotic oscillator involving cyclin and cdc2 kinase. Proc. Natl. Acad. Sci. USA 88 (1991), 9107-9111.

[6] B. Novak, J.J. Tyson. Numerical analysis of a comprehensive model of M-phase control in Xenopus oocyte extracts and intact embryos. J. Cell. Sci. 106 (1993), 1153-1168.

[7] J.E. Jr Ferrell, E.M Machleder. The biochemical basis of an all-or-none cell fate switch in Xenopus oocytes. Science 280 (1998), 895-898.

[8] J.R. Pomerening, E.D. Sontag, J.E. Jr Ferrell. Building a cell cycle oscillator: hysteresis and bistability in the activation of Cdc2. Nat. Cell. Biol. 5 (2003), 346-351.

[9] W. Sha, J. Moore, K. Chen, A.D. Lassaleta, C-S Yi, J.J. Tyson, J.C. Sible. Hysteresis drives cell-cycle transitions in Xenopus laevis egg extracts. Proc. Natl. Acad. Sci. USA 100 (2003), 975-980.

[10] B. Novak, J.J. Tyson. Modeling the control of DNA replication in fission yeast. Proc. Natl. Acad. Sci. USA 94 (1997), 9147-9152.

[11] K.C. Chen, L. Calzone, A. Csikasz-Nagy, F.R. Cross, B. Novak, J.J. Tyson. Integrative analysis of cell cycle control in budding yeast. Mol. Biol. Cell. 15 (2004), 3841-3862.

[12] D. Barik, W.T. Baumann, M.R. Paul, B. Novak, J.J. Tyson. A model of yeast cell-cycle regulation based on multisite phosphorylation. Mol. Syst. Biol. 6 (2010), 405.

[13] D.O. Morgan. Principles of Cdk regulation. Nature 374 (1995), 131-134.

[14] D.O. Morgan. The Cell Cycle : Principles of Control. Oxford Univ Press, UK, (2006).

[15] Z. Qu, J.N. Weiss, W.R. MacLellan. Regulation of the mammalian cell cycle: a model of the G1-to-S transition. Am. J. Physiol. Cell. Physiol. 284 (2003), 349-364.

[16] M. Swat, A. Kel, H. Herzel. Bifurcation analysis of the regulatory modules of the mammalian G1/S transition. Bioinformatics 20 (2004), 1506-1511.

[17] B. Pfeuty, T. David-Pfeuty, K. Kaneko. Underlying principles of cell fate determination during G1 phase of the mammalian cell cycle. Cell Cycle 7 (2008), 3246-3257.

[18] B. Novak, J.J. Tyson. A model for restriction point control of the mammalian cell cycle. J. Theor. Biol. 230 (2004), $563-579$. 
[19] E. He, O. Kapuy, R.A. Oliveira, F. Uhlmann, J.J. Tyson, B. Novak. System-level feedbacks make the anaphase switch irreversible. Proc. Natl. Acad. Sci. USA 108 (2011), 10016-10021.

[20] C. Gérard, A. Goldbeter. Temporal self-organization of the cyclin/Cdk network driving the mammalian cell cycle. Proc. Natl. Acad. Sci. USA 106 (2009), 21643-21648.

[21] C. Gérard, A. Goldbeter. A skeleton model for the network of cyclin-dependent kinases driving the mammalian cell cycle. Interface Focus 1 (2011), 24-35.

[22] C. Gérard, D. Gonze, A. Goldbeter. Effect of positive feedback loops on the robustness of oscillations in the network of cyclin-dependent kinases driving the mammalian cell cycle. FEBS J. 279 (2012), 3411-3431.

[23] A. Chauhan, S. Lorenzen, H. Herzel, S. Bernard. Regulation of mammalian cell cycle progression in the regenerating liver. J. Theor. Biol. 283 (2011), 103-112.

[24] C. Gérard, A. Goldbeter. Entrainment of the mammalian cell cycle by the circadian clock: Modeling two coupled cellular rhythms. PLoS Comput. Biol. 8(5): e1002516, (2012).

[25] E. Filipski, V.M. King, X.M. Li, T.G. Granda, M.C. Mormont, X. Liu, B. Claustrat, M.H. Hastings, F. Lévi. Host circadian clock as a control point in tumor progression. J. Natl. Cancer Inst. 94 (2002), 690-697.

[26] L. Fu, C.C. Lee. The circadian clock: pacemaker and tumour suppressor. Nature 3 (2003), 350-361.

[27] J.S. Pendergast, M. Yeom, B.A. Reyes, Y. Ohmiya, S. Yamazaki. Disconnected circadian and cell cycles in a tumordriven cell line. Commun. Integr. Biol. 3 (2010), 536-539.

[28] L.A. Segel. On the validity of the steady state assumption of enzyme kinetics. Bull. Math. Biol. 50 (1988), $579-593$.

[29] J.A. Borghans, R.J. de Boer, L.A. Segel. Extending the quasi-steady state approximation by changing variables. Bull. Math. Biol. 58 (1996), 43-63.

[30] A. Ciliberto, F. Capuani, J.J. Tyson. Modeling networks of coupled enzymatic reactions using the total quasi-steady state approximation. PLoS Comput. Biol. 3:e45, (2007).

[31] W. Zachariae, K. Nasmyth. Whose end is destruction: cell division and the anaphase-promoting complex. Genes Dev. 13 (1999), 2039-2058.

[32] E.R. Kramer, N. Scheuringer, A.V. Podtelejnikov, M. Mann, J.M. Peters. Mitotic regulation of the APC activator proteins CDC20 and CDH1. Mol. Biol. Cell. 11 (2000), 1555-1569.

[33] I. Hoffmann, P.R. Clarke, M.J. Marcote, E. Karsenti, G. Draetta. Phosphorylation and activation of human cdc25-C by cdc2-cyclin B and its involvement in the self-amplification of MPF at mitosis. EMBO J. 12 (1993), 53-63.

[34] M. Sabouri-Ghomi, A. Ciliberto, S. Kar, B. Novak, J.J. Tyson. Antagonism and bistability in protein interaction networks. J. Theor. Biol. 250 (2008), 209-218.

[35] A. Goldbeter, D.E. Jr Koshland. An amplified sensitivity arising from covalent modification in biological systems. Proc. Natl. Acad. Sci. USA 78 (1981), 6840-6844.

[36] H. Matsushime, D.E. Quelle, S.A. Shurtleff, M. Shibuya, C.J. Sherr, J-Y Kato. D-type cyclin-dependent kinase activity in mammalian cells. Mol. Cell. Biol. 14 (1994), 2066-2076.

[37] A. Goldbeter, C. Gérard, J-C Leloup. Biologie des systèmes et rythmes cellulaires. Médecine/Sciences 26 (2010), 49-56.

[38] A. Goldbeter, C. Gérard, J-C Leloup, D. Gonze, G. Dupont. Systems biology of cellular rhythms. FEBS Lett. 586 (2012), 2955-2965.

[39] C. Gérard, A. Goldbeter. From simple to complex patterns of oscillatory behavior in a model for the mammalian cell cycle containing multiple oscillatory circuits. Chaos 20 (2010), 045109.

[40] S. Mittnacht. Control of pRB phosphorylation. Curr. Opin. Genet. Dev. 8 (1998), 21-27.

[41] J.W. Harbour, D.C. Dean. The Rb/E2F pathway: expanding roles and emerging paradigms. Genes Dev. 14 (2000), 2393-2409.

[42] J-H Dannenberg, A. van Rossum, L. Schuijff, H. te Riele. Ablation of the Retinoblastoma gene family deregulates G1 control causing immortalization and increased cell turnover under growth-restricting conditions. Genes Dev. 14 (2000), 3051-3064.

[43] J. Sage, G.J. Mulligan, L.D. Attardi, A. Miller, S. Chen, B. Williams, E. Theodorou, T. Jacks. Targeted disruption of the three Rb-related genes leads to loss of G1 control and immortalization. Genes Dev. 14 (2000), 3037-3050.

[44] J.R. Pomerening, S.Y. Kim, J.E. Jr Ferrell. Systems-level dissection of the cell-cycle oscillator: bypassing positive feedback produces damped oscillations. Cell 122 (2005), 565-578.

[45] D. Gonze, M. Hafner. Positive feedbacks contribute to the robustness of the cell cycle with respect to molecular noise. Adv. in theory of control, signals. LNCIS 407, (2010) pp. 283-295 (Lévine J \& Müllhaupt P, eds), Springer-Verlag Berlin Heidelberg, Germany.

[46] C. Gérard, A. Goldbeter. From quiescence to proliferation: Cdk oscillations drive the mammalian cell cycle. Front. Physiol. 3 (2012), 413.

[47] A. Altinok, D. Gonze, F. Lévi, A. Goldbeter. An automaton model for the cell cycle. Interface Focus 1 (2011), $36-47$.

[48] A. Altinok, F. Lévi, A. Goldbeter. A cell cycle automaton model for probing circadian patterns of anticancer drug delivery. Adv. Drug Deliv. Rev. 59 (2007), 1036-1053.

[49] S. Kauffman. Measuring a mitotic oscillator: The arc discontinuity. Bull. Math. Biol. 36 (1974), $171-82$.

[50] S. Kauffman, J.J. Wille. The mitotic oscillator in Physarum polycephalum. J. Theor. Biol. 55 (1975), 47-93.

[51] A.T. Winfree. Discontinuities and singularities in the timing of nuclear division. In: Cell Cycle Clocks. L.N. Edmunds Jr, ed. Marcel Dekker, New York and Basel, (1984) pp. 63-80.

[52] L.N. Jr. Edmunds. Cellular and Molecular Bases of Biological Clocks. Models and Mechanisms for Circadian Timekeeping. Springer, New York (1988). 
[53] A. Boiteux, A. Goldbeter, B. Hess. Control of oscillating glycolysis of yeast by stochastic, periodic, and steady source of substrate: a model and experimental study. Proc. Natl. Acad. Sci. USA 72 (1975), 3829-3833.

[54] A.T. Winfree. The Geometry of Biological Time. Springer, New York (Reprinted as Springer Study Edition, 1990, Springer, Berlin, 1980).

[55] J.-C. Leloup, A. Goldbeter. A molecular explanation for the long-term suppression of circadian rhythms by a single light pulse. Am. J. Physiol. Reg. Integr. Comp. Physiol. 280 (2001), R1206-R1212.

[56] D. Gonze, A. Goldbeter. A model for a network of phosphorylation-dephosphorylation cycles displaying the dynamics of dominoes and clocks. J Theor Biol 210 (2001), 167-186. (See erratum : J. Theor. Biol. 212 (2001)), 565.

[57] A.W. Murray, M.W. Kirschner. Dominoes and clocks: The union of two views of the cell cycle. Science 246 (1989), 614-621.

[58] I. Conlon, M. Raff. Differences in the way a mammalian cell and yeast cells coordinate cell growth and cell-cycle progression. J. Biol. 2 (2003), 7. 


\section{Appendix}

\section{The cell cycle is a limit cycle}

Claude Gérard and Albert Goldbeter

1. Extended version of the skeleton, 5-variable, model for the mammalian cell cycle

Time evolution of the transcription factor E2F, cyclin E/Cdk2 (Me), cyclin A/Cdk2 (Ma), cyclin $\mathrm{B} / \mathrm{Cdk} 1(\mathrm{Mb})$ and the protein Cdc20 describing the Cdk network driving the cell cycle in the 5variable model is described below as Eqs. [1] to [5] (see also Gérard et al., 2012). The time evolution of cyclin D/Cdk4-6 (Md) is decoupled from the other variables of the model and depends only on the level of growth factor (GF), so as the level of cyclin D/Cdk4-6 rapidly reaches a stable steady state. A list defining and giving the numerical values of all parameters used in this model are shown in Table 1.

$$
\begin{aligned}
& \frac{d E 2 F}{d t}=\left(V_{1 e 2 f} \cdot\left(\frac{\left(E 2 F_{t o t}-E 2 F\right)}{K_{1 e 2 f}+\left(E 2 F_{t o t}-E 2 F\right)}\right) \cdot(M d+M e)-V_{2 e 2 f} \cdot\left(\frac{E 2 F}{K_{2 e 2 f}+E 2 F}\right) \cdot M a\right) \cdot \mu \\
& \frac{d M e}{d t}=\left(V_{1 M e} \cdot E 2 F \cdot\left(a+b_{1} \cdot M e\right) \cdot\left(\frac{M e_{t o t}-M e}{K_{1 M e}+\left(M e_{t o t}-M e\right)}\right)-V_{2 M e} \cdot M a \cdot\left(\frac{M e}{K_{2 M e}+M e}\right)\right) \cdot \mu \\
& \frac{d M a}{d t}=\left(V_{1 M a} \cdot E 2 F \cdot\left(\frac{M a_{t o t}-M a}{K_{1 M a}+\left(M a_{t o t}-M a\right)}\right)-V_{2 M a} \cdot C d c 20 \cdot\left(\frac{M a}{K_{2 M a}+M a}\right)\right) \cdot \mu \\
& \frac{d M b}{d t}=\left(V_{1 M b} \cdot M a \cdot\left(a+b_{2} \cdot M b\right) \cdot\left(\frac{K_{i e}}{K_{i e}+M e}\right) \cdot\left(\frac{M b_{t o t}-M b}{K_{1 M b}+\left(M b_{t o t}-M b\right)}\right)\right. \\
& \left.-V_{2 M b} \cdot\left(\frac{K_{i b}}{K_{i b}+M b}\right) \cdot C d c 20 \cdot\left(\frac{M b}{K_{2 M b}+M b}\right)\right) \cdot \mu \\
& \frac{d C d c 20}{d t}=\left(V_{1 c d c 20} \cdot M b \cdot\left(\frac{(C d c 20}{\left.K_{1 c d c 20}+C d c 20\right)}\right)-V_{2 c d c 20} \cdot\left(\frac{C d c 20}{K_{2 c t c 20}+C d c 20}\right)\right. \\
& \frac{d M d}{d t}=\left(v_{s d} \cdot\left(\frac{G F}{K_{g f}+G F}\right)-V_{d d} \cdot\left(\frac{M d}{K_{d d}+M d}\right)\right) \cdot \mu
\end{aligned}
$$


Table 1: Parameters of the skeleton model for the mammalian cell cycle

\begin{tabular}{|c|c|c|}
\hline$\underline{\text { Symbol }}$ & $\underline{\text { Definition }}$ & $\frac{\text { Numerical }}{\text { values }}$ \\
\hline$a$ & $\begin{array}{l}\text { Basal term of activation of cyclin E/Cdk2 and cyclin B/Cdk1 } \\
\text { (without positive feedback loop) }\end{array}$ & $1 \mu \mathrm{M}$ \\
\hline$\mu$ & Scaling parameter & 0.3 \\
\hline $\mathrm{Cdc20}$ tot & Total concentration of the protein $\mathrm{Cdc} 20$ & $1 \mu \mathrm{M}$ \\
\hline$E 2 F_{\text {tot }}$ & Total concentration of the transcription factor E2F & $1 \mu \mathrm{M}$ \\
\hline$G F$ & Growth factor & $1 \mu \mathrm{M}$ \\
\hline$M e_{\text {tot }}$ & Total concentration of cyclin E/Cdk2 & $1 \mu \mathrm{M}$ \\
\hline$M a_{\text {tot }}$ & Total concentration of cyclin $\mathrm{A} / \mathrm{Cdk} 2$ & $1 \mu \mathrm{M}$ \\
\hline$M b_{\text {tot }}$ & Total concentration of cyclin $\mathrm{B} / \mathrm{Cdk} 1$ & $1 \mu \mathrm{M}$ \\
\hline$K_{\mathrm{dd}}$ & Michaelis constant for degradation of cyclin D/Cdk4-6 complex & $0.1 \mu \mathrm{M}$ \\
\hline$K_{\mathrm{gf}}$ & $\begin{array}{c}\text { Michaelis constant for synthesis of cyclin D/Cdk4-6 complex } \\
\text { induced by growth factor }\end{array}$ & $0.1 \mu \mathrm{M}$ \\
\hline$K_{1 \mathrm{e} 2 \mathrm{f}}$ & $\begin{array}{l}\text { Michaelis constant for E2F activation by cyclin D/Cdk4-6 and cyclin } \\
\text { E/Cdk2 complexes }\end{array}$ & $0.005 \mu \mathrm{M}$ \\
\hline$K_{2 \mathrm{e} 2 \mathrm{f}}$ & Michaelis constant for E2F inactivation by cyclin $\mathrm{A} / \mathrm{Cdk} 2$ complex & $0.005 \mu \mathrm{M}$ \\
\hline$K_{1 \mathrm{Me}}$ & Michaelis constant for cyclin E/Cdk2 activation by E2F & $0.005 \mu \mathrm{M}$ \\
\hline$K_{2 \mathrm{Me}}$ & Michaelis constant for cyclin $\mathrm{E} / \mathrm{Cdk} 2$ inactivation by cyclin $\mathrm{A} / \mathrm{Cdk} 2$ & $0.005 \mu \mathrm{M}$ \\
\hline$K_{1 \mathrm{Ma}}$ & Michaelis constant for cyclin $\mathrm{A} / \mathrm{Cdk} 2$ activation by $\mathrm{E} 2 \mathrm{~F}$ & $0.005 \mu \mathrm{M}$ \\
\hline$K_{2 \mathrm{Ma}}$ & Michaelis constant for cyclin $\mathrm{A} / \mathrm{Cdk} 2$ inactivation by $\mathrm{Cdc} 20$ & $0.005 \mu \mathrm{M}$ \\
\hline$K_{1 \mathrm{Mb}}$ & Michaelis constant for cyclin $\mathrm{B} / \mathrm{Cdk} 1$ activation by cyclin $\mathrm{A} / \mathrm{Cdk} 2$ & $0.005 \mu \mathrm{M}$ \\
\hline$K_{2 \mathrm{Mb}}$ & Michaelis constant for cyclin $\mathrm{B} / \mathrm{Cdk} 1$ inactivation by $\mathrm{Cdc} 20$ & $0.005 \mu \mathrm{M}$ \\
\hline$K_{\text {lcdc20 }}$ & $\begin{array}{l}\text { Michaelis constant for Cdc20 activation through phosphorylation by } \\
\text { cyclin B/Cdk1 }\end{array}$ & $0.005 \mu \mathrm{M}$ \\
\hline$K_{2 \mathrm{cdc} 20}$ & Michaelis constant for Cdc20 inactivation through dephosphorylation & $0.005 \mu \mathrm{M}$ \\
\hline$K_{\text {ie }}$ & $\begin{array}{l}\text { Michaelis constant for cyclin } \mathrm{B} / \mathrm{Cdk} 1 \text { inactivation by cyclin } \mathrm{E} / \mathrm{Cdk} 2, \\
\text { which represents the indirect effect of the DNA replication } \\
\text { checkpoint (see [14]) }\end{array}$ & $0.2 \mu \mathrm{M}$ \\
\hline$V_{\mathrm{dd}}$ & Maximum degradation rate of cyclin $\mathrm{D} / \mathrm{Cdk} 4-6$ complex & $0.245 \mu \mathrm{M} . \mathrm{h}^{-1}$ \\
\hline$v_{\mathrm{sd}}$ & $\begin{array}{l}\text { Maximum rate for synthesis of cyclin D/Cdk4-6 induced by growth } \\
\text { factor GF }\end{array}$ & $0.175 \mu \mathrm{M} \cdot \mathrm{h}^{-1}$ \\
\hline$V_{\text {ldde20 }}$ & $\begin{array}{l}\text { Rate constant for activation of Cdc20 through phosphorylation by } \\
\text { cyclin } \mathrm{B} / \mathrm{Cdk} 1\end{array}$ & $4 \mathrm{~h}^{-1}$ \\
\hline$V_{2 \mathrm{cdc} 20}$ & $\begin{array}{c}\text { Maximum rate constant for inactivation of Cdc20 through } \\
\text { dephosphorylation }\end{array}$ & $0.6 \mu \mathrm{M} \cdot \mathrm{h}^{-1}$ \\
\hline$V_{\text {le2f }}$ & $\begin{array}{l}\text { Rate constant for activation of E2F by cyclin } \mathrm{D} / \mathrm{Cdk} 4-6 \text { and cyclin } \\
\qquad \mathrm{E} / \mathrm{Cdk} 2 \text { complexes }\end{array}$ & $0.35 \mathrm{~h}^{-1}$ \\
\hline$V_{2 \mathrm{e} 2 \mathrm{f}}$ & Rate constant for inactivation of E2F by cyclin $\mathrm{A} / \mathrm{Cdk} 2$ complex & $0.7 \mathrm{~h}^{-1}$ \\
\hline$V_{1 \mathrm{Me}}$ & Rate for activation of cyclin $\mathrm{E} / \mathrm{Cdk} 2$ by $\mathrm{E} 2 \mathrm{~F}$ & $1 \mu \mathrm{M}^{-1} \cdot \mathrm{h}^{-1}$ \\
\hline
\end{tabular}




\begin{tabular}{|c|c|c|}
\hline$V_{2 \mathrm{Me}}$ & Rate constant for inactivation of cyclin E/Cdk2 by cyclin A/Cdk2 & $1.6 \mathrm{~h}^{-1}$ \\
\hline$V_{1 \mathrm{Ma}}$ & Rate constant for activation of cyclin A/Cdk2 by E2F & $0.7 \mathrm{~h}^{-1}$ \\
\hline$V_{2 \mathrm{Ma}}$ & Rate constant for inactivation of cyclin A/Cdk2 by Cdc20 & $0.6 \mathrm{~h}^{-1}$ \\
\hline$V_{1 \mathrm{Mb}}$ & Rate for activation of cyclin B/Cdk1 by cyclin A/Cdk2 & $1.1 \mu \mathrm{M}^{-1} \cdot \mathrm{h}^{-1}$ \\
\hline$V_{2 \mathrm{Mb}}$ & Rate constant for inactivation of cyclin B/Cdk1 by Cdc20 & $0.8 \mathrm{~h}^{-1}$ \\
\hline$b_{1}$ & $\begin{array}{c}\text { Term representing the self-activation of cyclin E/Cdk2 through } \\
\text { mutual activation between cyclin E/Cdk2 and its phosphatase Cdc25 } \\
\text { (positive feedback loop in the G1/S transition) }\end{array}$ & 1 \\
\hline$b_{2}$ & $\begin{array}{c}\text { Term representing the self-activation of cyclin B/Cdk1 through } \\
\text { mutual activation between cyclin B/Cdk1 and its phosphatase Cdc25 } \\
\text { (positive feedback loop in the G2/M transition) }\end{array}$ & 1 \\
\hline$K_{\mathrm{ib}}$ & $\begin{array}{c}\text { Inhibition constant for Wee1 inactivation by cyclin B/Cdk1 } \\
\text { (the mutual inhibition of Wee1 and Cdk1 creates a positive feedback } \\
\text { loop in the G2/M transition) }\end{array}$ & $0.5 \mu \mathrm{M}$ \\
\hline
\end{tabular}


2. Detailed model of 80 variables based on mass-action kinetics

The system of 80 kinetic equations is represented module per module. A list of all variables of the model is shown in Table 2, while a list defining and giving the numerical values of all parameters used in this model is presented in Table 3.

Mitotic stimulation by growth factor (GF)

$\frac{d A P 1}{d t}=\left(V_{\text {sap } 1} \cdot\left(\frac{G F}{K_{a g f}+G F}\right)-k_{d a p 1} \cdot A P 1\right) \cdot e p s$

Antagonistic Regulations between pRB and E2F

$$
\begin{aligned}
& \frac{d p R B}{d t}=\left(v_{s p R B}-k_{p c 1} \cdot p R B \cdot E 2 F+k_{p c 2} \cdot p R B c 1-k_{3 p R B} \cdot p R B \cdot M d p 27\right. \\
& \left.+k_{4 p R B} \cdot M d p 27 p R B-k_{1 p R B} \cdot M d \cdot p R B+k_{2 p R B} \cdot M d p R B-k_{d d p R B} \cdot p R B\right) \cdot e p s \\
& \frac{d p R B c 1}{d t}=\left(k_{p c 1} \cdot p R B \cdot E 2 F-k_{p c 2} \cdot p R B c 1\right) \cdot e p s \\
& \frac{d p R B p}{d t}=\left(k_{i 1 p R B} \cdot M d p R B+k_{i 2 p R B} \cdot M d p 27 p R B-k_{1 p R B p} \cdot M e \cdot p R B p\right. \\
& \left.+k_{2 p R B p} \cdot M e p R B p-k_{p c 3} \cdot p R B p \cdot E 2 F+k_{p c 4} \cdot p R B c 2-k_{d d p R B p} \cdot p R B p\right) \cdot e p s \\
& \frac{d p R B c 2}{d t}=\left(k_{p c 3} \cdot p R B p \cdot E 2 F-k_{p c 4} \cdot p R B c 2\right) \cdot e p s \\
& \frac{d p R B p p}{d t}=\left(k_{i 3 p R B} \cdot M e p R B p-k_{d d p R B p p} \cdot p R B p p\right) \cdot e p s \\
& \frac{d E 2 F}{d t}=\left(v_{s e 2 f}-k_{1 e 2 f} \cdot E 2 F \cdot M a+k_{2 e 2 f} \cdot E 2 F M a-k_{p c 1} \cdot p R B \cdot E 2 F+k_{p c 2} \cdot p R B c 1\right. \\
& \left.-k_{p c 3} \cdot p R B p \cdot E 2 F+k_{p c 4} \cdot p R B c 2-k_{d d e 2 f} \cdot E 2 F\right) \cdot e p s \\
& \frac{d E 2 F u}{d t}=\left(k_{a d e 2 f} \cdot E 2 F M a-k_{d e 2 f u} \cdot E 2 F u-k_{d d e 2 f u} \cdot E 2 F u\right) \cdot e p s \\
& \frac{d E 2 F M a}{d t}=\left(k_{1 e 2 f} \cdot M a \cdot E 2 F-k_{2 e 2 f} \cdot E 2 F M a-k_{a d e 2 f} \cdot E 2 F M a\right) \cdot e p s \\
& \frac{d M d p R B}{d t}=\left(k_{1 p R B} \cdot p R B \cdot M d-k_{2 p R B} \cdot M d p R B-k_{i 1 p R B} \cdot M d p R B\right) \cdot \text { eps } \\
& \frac{d M d p 27 p R B}{d t}=\left(k_{3 p R B} \cdot M d p 27 \cdot p R B-k_{4 p R B} \cdot M d p 27 p R B\right. \\
& \text { - } \left.k_{i 2 p R B} \cdot M d p 27 p R B\right) \cdot e p s
\end{aligned}
$$


$\frac{d M e p R B p}{d t}=\left(k_{1 p R B p} \cdot M e \cdot p R B p-k_{2 p R B p} \cdot M e p R B p-k_{i 3 p R B} \cdot M e p R B p\right) \cdot e p s$

$\underline{\text { Module Cyclin D/CDk4-6: G1 phase }}$

$\frac{d C d}{d t}=\left(k_{c d 1} \cdot A P 1+k_{c d 2} \cdot E 2 F \cdot\left(\frac{K_{i 7}}{K_{i 7}+p R B}\right) \cdot\left(\frac{K_{i 8}}{K_{i 8}+p R B p}\right)\right.$

$-k_{\text {com } 1} \cdot C d \cdot\left(C d k 4_{t o t}-(M d i+M d+M d p 27+M d P d+k i n 1 M d i\right.$

[13]

$\left.+M d p R B+M d p 27 p R B))+k_{\text {decom } 1} \cdot M d i-k_{d d C d} \cdot C d\right) \cdot e p s$

$\frac{d M d i}{d t}=\left(k_{c o m 1} \cdot C d \cdot\left(C d k 4_{t o t}-(M d i+M d+M d p 27+M d P d+k i n 1 M d i+M d p R B\right.\right.$

$+M d p 27 p R B))-k_{d e c o m 1} \cdot M d i-k_{1 M d i} \cdot M d i \cdot\left(k i n 1_{t o t}-k i n 1 M d i\right)+k_{2 M d i} \cdot k i n 1 M d i$

$\left.+k_{1 i d} \cdot M d P d\right) \cdot e p s$

$\frac{d M d}{d t}=\left(k_{1 a d} \cdot k i n 1 M d i-k_{c 1} \cdot M d \cdot p 27+k_{c 2} \cdot M d p 27-k_{1 p R B} \cdot M d \cdot p R B\right.$

$+k_{2 p R B} \cdot M d p R B+k_{i 1 p R B} \cdot M d p R B-k_{1 M d} \cdot M d \cdot\left(P d_{t o t}-M d P d\right)$

[15]

$\left.+k_{2 M d} \cdot M d P d\right) \cdot e p s$

$\frac{d M d p 27}{d t}=\left(k_{c 1} \cdot M d \cdot p 27-k_{c 2} \cdot M d p 27-k_{3 p R B} \cdot M d p 27 \cdot p R B+k_{4 p R B} \cdot M d p 27 p R B\right.$

$\left.+k_{i 2 p R B} \cdot M d p 27 p R B\right) \cdot e p s$

[16]

$\frac{d M d P d}{d t}=\left(k_{1 M d} \cdot M d \cdot\left(P d_{t o t}-M d P d\right)-k_{2 M d} \cdot M d P d-k_{1 i d} \cdot M d P d\right) \cdot e p s$

$\frac{d P d}{d t}=\left(k_{2 M d} \cdot M d P d-k_{1 M d} \cdot M d \cdot\left(P d_{t o t}-M d P d\right)+k_{1 i d} \cdot M d P d\right) \cdot e p s$

$\frac{d k i n 1}{d t}=\left(k_{2 M d i} \cdot k i n 1 M d i-k_{1 M d i} \cdot M d i \cdot\left(k i n 1_{t o t}-k i n 1 M d i\right)+k_{1 a d} \cdot k i n 1 M d i\right) \cdot e p s$

$\frac{d k i n 1 M d i}{d t}=\left(k_{1 M d i} \cdot M d i \cdot\left(k i n 1_{t o t}-k i n 1 M d i\right)-k_{2 M d i} \cdot k i n 1 M d i-k_{1 a d} \cdot k i n 1 M d i\right) \cdot e p s$

Module Cyclin E/CDk2: G1 phase and G1/S transition

$\frac{d C e}{d t}=\left(k_{c e 1}+k_{c e 2} \cdot E 2 F \cdot\left(\frac{K_{i 9}}{K_{i 9}+p R B}\right) \cdot\left(\frac{K_{i 10}}{K_{i 10}+p R B p}\right)\right.$

$-k_{\text {com } 2} \cdot C e \cdot\left(C d k 2_{\text {tot }}-(M e i+M e+M e P e i+M e p 27+M e i P e+k i n 2 M e\right.$

+ MepRBp + Mai + Ma+MaiPa+MaPai + Map27+MaCdh1+kin3Ma

$+E 2 F M a+M a W e e 1+M e W e e 1))+k_{\text {decom } 2} \cdot M e i-k_{\text {leskp } 2} \cdot C e \cdot S k p 2$

$\left.+k_{2 e s k p 2} \cdot \operatorname{Ceskp2}-k_{d d C e} \cdot C e\right) \cdot e p s$ 
$\frac{d M e i}{d t}=\left(k_{\text {com } 2} \cdot C e \cdot\left(C d k 2_{t o t}-(M e i+M e+M e P e i+M e p 27+M e i P e+k i n 2 M e\right.\right.$

+ MepRBp + Mai + Ma+MaiPa + MaPai + Map27+MaCdh1+kin3Ma

$+E 2 F M a+M a W e e 1+M e W e e 1))-k_{\text {decom } 2} \cdot M e i-k_{1 M e i} \cdot M e i \cdot P e$

$\left.+k_{2 M e i} \cdot M e i P e+k_{1 i e} \cdot k i n 2 M e+k_{\text {imeweel }} \cdot M e W e e 1\right) \cdot e p s$

$\frac{d M e}{d t}=\left(k_{1 a e} \cdot M e i P e-k_{c 3} \cdot M e \cdot p 27+k_{c 4} \cdot M e p 27-k_{1 P e i} \cdot M e \cdot P e i+k_{2 P e i} \cdot M e P e i\right.$

$+k_{2 a e} \cdot M e P e i+k_{2 p R B p} \cdot M e p R B p-k_{1 p R B p} \cdot M e \cdot p R B p+k_{i 3 p R B} \cdot M e p R B p$

$-k_{1 M e} \cdot M e \cdot\left(k i n 2_{t o t}-k i n 2 M e\right)+k_{2 M e} \cdot k i n 2 M e+k_{i p 27} \cdot M e p 27-k_{1 m e w e e 1} \cdot M e \cdot$ Wee 1

[23]

$\left.+k_{2 \text { meweel }} \cdot \mathrm{MeWee} 1\right) \cdot \mathrm{eps}$

$\frac{d P e i}{d t}=\left(k_{s P e i}-k_{1 P e i} \cdot M e \cdot P e i+k_{2 P e i} \cdot M e P e i-k_{d d P e i} \cdot P e i\right) \cdot e p s$

$\frac{d M e P e i}{d t}=\left(k_{1 P e i} \cdot M e \cdot P e i-k_{2 P e i} \cdot M e P e i-k_{2 a e} \cdot M e P e i\right) \cdot e p s$

$\frac{d P e}{d t}=\left(k_{2 M e i} \cdot M e i P e-k_{1 M e i} \cdot P e \cdot M e i+k_{1 a e} \cdot M e i P e+k_{2 a e} \cdot M e P e i-k_{d d P e} \cdot P e\right) \cdot e p s$

$\frac{d M e p 27}{d t}=\left(k_{c 3} \cdot p 27 \cdot M e-k_{c 4} \cdot M e p 27-k_{i p 27} \cdot M e p 27\right) \cdot e p s$

$\frac{d S k p 2}{d t}=\left(v_{s s k p 2}-k_{1 e s k p 2} \cdot S k p 2 \cdot C e+k_{2 e s k p 2} \cdot \operatorname{CeSkp2}-k_{1 e c d h 1} \cdot \operatorname{Skp} 2 \cdot \operatorname{Cdh} 1 a\right.$

$+k_{2 e c d h 1} \cdot C d h 1 S k p 2-k_{127 s k 2} \cdot S k p 2 \cdot p 27 p+k_{227 s k 2} \cdot p 27 p S k p 2$

$\left.+k_{d a 27 p} \cdot p 27 p S k p 2+k_{4 d} \cdot \operatorname{CeSkp2}-k_{d d s k p 2} \cdot S k p 2\right) \cdot e p s$

$\frac{d \operatorname{CeSkp2}}{d t}=\left(k_{1 e s k p 2} \cdot \operatorname{Skp} 2 \cdot \operatorname{Ce}-k_{2 e s k p 2} \cdot \operatorname{CeSkp} 2-k_{4 d} \cdot \operatorname{CeSkp2}-k_{d d 6} \cdot \operatorname{CeSkp} 2\right) \cdot$ eps

$\frac{d C e u}{d t}=\left(k_{4 d} \cdot \operatorname{CeSkp2}-k_{d C e u} \cdot C e u-k_{d d C e u} \cdot C e u\right) \cdot e p s$

$\frac{d C d h 1 S k p 2}{d t}=\left(k_{1 e c d h 1} \cdot S k p 2 \cdot C d h 1 a-k_{2 e c d h 1} \cdot C d h 1 S k p 2-k_{5 d} \cdot C d h 1 S k p 2\right.$

$\left.-k_{d d 7} \cdot C d h 1 S k p 2\right) \cdot e p s$

$\frac{d S k p 2 u}{d t}=\left(k_{5 d} \cdot C d h 1 S k p 2-k_{d s k p 2 u} \cdot \operatorname{Skp} 2 u-k_{d d s k p 2 u} \cdot \operatorname{Skp} 2 u\right) \cdot \operatorname{eps}$

$\frac{d M e i P e}{d t}=\left(k_{1 M e i} \cdot P e \cdot M e i-k_{2 M e i} \cdot M e i P e-k_{1 a e} \cdot M e i P e\right) \cdot e p s$

$\frac{d k i n 2}{d t}=\left(k_{2 M e} \cdot k i n 2 M e-k_{1 M e} \cdot M e \cdot\left(k i n 2_{t o t}-k i n 2 M e\right)+k_{1 i e} \cdot k i n 2 M e\right) \cdot e p s$ 
$\frac{d k i n 2 M e}{d t}=\left(k_{1 M e} \cdot M e \cdot\left(k i n 2_{t o t}-k i n 2 M e\right)-k_{2 M e} \cdot k i n 2 M e-k_{1 i e} \cdot k i n 2 M e\right) \cdot e p s$

$\frac{d M e W e e 1}{d t}=\left(k_{1 \text { meweel }} \cdot M e \cdot W e e 1-k_{2 m e w e e 1} \cdot M e W e e 1-k_{\text {imeweel }} \cdot M e W e e 1\right) \cdot e p s$

\section{Module Cyclin A/Cde 2: S phase and S/G2 transition}

$\frac{d C a}{d t}=\left(k_{c a 1}+k_{c a 2} \cdot E 2 F \cdot\left(\frac{K_{i 11}}{K_{i 11}+p R B}\right) \cdot\left(\frac{K_{i 12}}{K_{i 12}+p R B p}\right)\right.$

$-k_{\text {com } 3} \cdot C a \cdot\left(C d k 2_{\text {tot }}-(M e i+M e+M e P e i+M e p 27+M e i P e+k i n 2 M e+M e p R B p\right.$

+Mai+Ma+MaiPa+MaPai + Map27+MaCdh1+kin3Ma+E2FMa

$+\mathrm{MaWee} 1+\mathrm{MeWee1}))+k_{\text {decom } 3} \cdot \mathrm{Mai}-k_{1 a c d c 20} \cdot \mathrm{Ca} \cdot \mathrm{Cdc} 20$

$\left.+k_{2 a c d c 20} \cdot C d c 20 C a-k_{d d C a} \cdot C a\right) \cdot e p s$

$\frac{d M a i}{d t}=\left(k_{\text {com } 3} \cdot C a \cdot\left(C d k 2_{t o t}-(M e i+M e+M e P e i+M e p 27+M e i P e+k i n 2 M e\right.\right.$

+ MepRBp+Mai+Ma+MaiPa+MaPai + Map27+MaCdh1+kin3Ma

$+E 2 F M a+M a W e e 1+M e W e e 1))-k_{\text {decom } 3} \cdot M a i-k_{1 M a i} \cdot M a i \cdot P a$

[38]

$\left.+k_{2 M a i} \cdot M a i P a+k_{1 i a} \cdot k i n 3 M a+k_{\text {imawee }} \cdot M a W e e 1\right) \cdot e p s$

$\frac{d M a}{d t}=\left(k_{2 e 2 f} \cdot E 2 F M a-k_{1 e 2 f} \cdot M a \cdot E 2 F+k_{a d e 2 f} \cdot E 2 F M a+k_{1 a a} \cdot M a i P a\right.$

$-k_{c 5} \cdot M a \cdot p 27+k_{c 6} \cdot M a p 27-k_{1 P a i} \cdot M a \cdot P a i+k_{2 P a i} \cdot M a P a i+k_{2 a a} \cdot M a P a i$

$-k_{1 c d h 1} \cdot M a \cdot C d h 1 a+k_{2 c d h 1} \cdot M a C d h 1+k_{i c d h 1} \cdot M a C d h 1-k_{1 M a} \cdot M a \cdot\left(k i n 3_{t o t}-k i n 3 M a\right)$

[39]

$+k_{2 M a} \cdot \operatorname{kin} 3 \mathrm{Ma}-k_{1 \text { mawee } 1} \cdot M a \cdot$ Wee $\left.1+k_{2 \text { maweel }} \cdot M a W e e 1\right) \cdot$ eps

$\frac{d p 27}{d t}=\left(v_{s 1 p 27}+v_{s 2 p 27} \cdot E 2 F \cdot\left(\frac{K_{i 13}}{K_{i 13}+p R B}\right) \cdot\left(\frac{K_{i 14}}{K_{i 14}+p R B p}\right)+k_{c 2} \cdot M d p 27\right.$

$-k_{c 1} \cdot M d \cdot p 27+k_{c 4} \cdot M e p 27-k_{c 3} \cdot M e \cdot p 27+k_{c 6} \cdot M a p 27-k_{c 5} \cdot M a \cdot p 27$

$\left.+k_{c 8} \cdot M b p 27-k_{c 7} \cdot M b \cdot p 27-k_{d d p 27} \cdot p 27\right) \cdot e p s$

$\frac{d p 27 p}{d t}=\left(k_{i p 27} \cdot M e p 27-k_{127 s k 2} \cdot S k p 2 \cdot p 27 p+k_{227 s k 2} \cdot p 27 p S k p 2\right.$

$\left.-k_{d p 27 p} \cdot p 27 p\right) \cdot e p s$

$\frac{d p 27 p S k p 2}{d t}=\left(k_{127 s k 2} \cdot S k p 2 \cdot p 27 p-k_{227 s k 2} \cdot p 27 p S k p 2-k_{d a 27 p} \cdot p 27 p S k p 2\right) \cdot e p s$

$\frac{d p 27 u}{d t}=\left(k_{d a 27 p} \cdot p 27 p S k p 2-k_{d p 27 u} \cdot p 27 u\right) \cdot e p s$

$\frac{d M a p 27}{d t}=\left(k_{c 5} \cdot M a \cdot p 27-k_{c 6} \cdot M a p 27\right) \cdot e p s$ 
$\frac{d C d h 1 i}{d t}=\left(k_{i c d h 1} \cdot M a C d h 1+k_{i c d h 1 b} \cdot M b C d h 1+k_{2 a c d h 1} \cdot P h o s c d h 1\right.$

- $\left.k_{1 a c d h 1} \cdot\left(P h o s 3_{t o t}-P h o s C d h 1\right) \cdot C d h 1 i-k_{d d C d h 1 i} \cdot C d h 1 i\right) \cdot$ eps

$\frac{d C d h 1 a}{d t}=\left(v_{s c d h 1}-k_{1 c d h 1} \cdot C d h 1 a \cdot M a+k_{2 c d h 1} \cdot M a C d h 1-k_{1 c d h 1 b} \cdot C d h 1 a \cdot M b\right.$

$+k_{2 c d h 1 b} \cdot M b C d h 1-k_{1 b c d h 1} \cdot C d h 1 a \cdot C b+k_{2 b c d h 1} \cdot C d h 1 C b+k_{3 d} \cdot C d h 1 C b$

$-k_{1 e c d h 1} \cdot C d h 1 a \cdot S k p 2+k_{2 e c d h 1} \cdot C d h 1 S k p 2+k_{a c d h 1} \cdot P h o s C d h 1$

$\left.+k_{5 d} \cdot C d h 1 S k p 2-k_{d d c d h 1 a} \cdot C d h 1 a\right) \cdot e p s$

$\frac{d M b C d h 1}{d t}=\left(k_{1 c d h 1 b} \cdot C d h 1 a \cdot M b-k_{2 c d h 1 b} \cdot M b C d h 1-k_{i c d h 1 b} \cdot M b C d h 1\right) \cdot e p s$

$\frac{d P h o s 3}{d t}=\left(k_{2 a c d h 1} \cdot P h o s C d h 1-k_{1 a c d h 1} \cdot\left(P h o s 3_{t o t}-P h o s C d h 1\right) \cdot C d h 1 i\right.$

$+k_{a c d h 1} \cdot P h o s(d h 1) \cdot e p s$

$\frac{d P h o s C d h 1}{d t}=\left(k_{1 a c d h 1} \cdot\left(P h o s 3_{t o t}-P h o s C d h 1\right) \cdot C d h 1 i-k_{2 a c d h 1} \cdot P h o s C d h 1\right.$

$\left.-k_{a c d h 1} \cdot \operatorname{Phos} C d h 1\right) \cdot e p s$

[49]

$\frac{d P a i}{d t}=\left(k_{\text {spai }}-k_{1 p a i} \cdot P a i \cdot M a+k_{2 p a i} \cdot M a P a i-k_{d d p a i} \cdot P a i\right) \cdot e p s$

$\frac{d P a}{d t}=\left(k_{2 m a i} \cdot M a i P a-k_{1 m a i} \cdot P a \cdot M a i+k_{1 a a} \cdot M a i P a+k_{2 a a} \cdot M a P a i-k_{d d p a} \cdot P a\right) \cdot e p s$

$\frac{d M a i P a}{d t}=\left(k_{1 m a i} \cdot P a \cdot M a i-k_{2 m a i} \cdot M a i P a-k_{1 a a} \cdot M a i P a\right) \cdot e p s$

$\frac{d M a P a i}{d t}=\left(k_{1 p a i} \cdot P a i \cdot M a-k_{2 p a i} \cdot M a P a i-k_{2 a a} \cdot M a P a i\right) \cdot e p s$

$\frac{d M a C d h 1}{d t}=\left(k_{1 c d h 1} \cdot M a \cdot C d h 1 a-k_{2 c d h 1} \cdot M a C d h 1-k_{i c d h 1} \cdot M a C d h 1\right) \cdot e p s$

[54]

$\frac{d C d c 20 C a}{d t}=\left(k_{1 a c d c 20} \cdot C a \cdot C d c 20-k_{2 a c d c 20} \cdot C d c 20 C a-k_{2 d} \cdot C d c 20 C a\right.$

$\left.-k_{d d 3} \cdot C d c 20 C a\right) \cdot e p s$

$\frac{d C d h 1 C b}{d t}=\left(k_{1 b c d h 1} \cdot C d h 1 a \cdot C b-k_{2 b c d h 1} \cdot C d h 1 C b-k_{3 d} \cdot C d h 1 C b\right.$

$\left.-k_{d d C d h 1 C b} \cdot C d h 1 C b\right) \cdot e p s$

$\frac{d C a u}{d t}=\left(k_{2 d} \cdot C d c 20 C a-k_{d C a u} \cdot C a u-k_{d d C a u} \cdot C a u\right) \cdot$ eps 
$\frac{d k i n 3}{d t}=\left(k_{2 M a} \cdot k i n 3 M a-k_{1 M a} \cdot M a \cdot\left(k i n 3_{t o t}-k i n 3 M a\right)+k_{1 i a} \cdot k i n 3 M a\right) \cdot e p s$

$\frac{d k i n 3 M a}{d t}=\left(k_{1 M a} \cdot M a \cdot\left(k i n 3_{t o t}-k i n 3 M a\right)-k_{2 M a} \cdot k i n 3 M a-k_{1 i a} \cdot k i n 3 M a\right) \cdot e p s$

$\frac{d M a W e e 1}{d t}=\left(k_{1 \text { mawee } 1} \cdot M a \cdot W e e 1-k_{2 m a w e e 1} \cdot M a W e e 1-k_{\text {imawee1 }} \cdot M a W e e 1\right) \cdot e p s$

\section{Module Cyclin B/Cdk1: G2 phase and G2/M transition}

$\frac{d C b}{d t}=\left(k_{c b}-k_{c o m 4} \cdot C b \cdot\left(C d k 1_{t o t}-(M b i+M b+M b p 27+M b W e e 1+M b i P b\right.\right.$

$+M b P b i+M b C d c 20 i+M b C d h 1))+k_{\text {decom } 4} \cdot M b i-k_{1 b c d c 20} \cdot C d c 20 \cdot C b$

$\left.+k_{2 b c d c 20} \cdot C d c 20 C b-k_{1 b c d h 1} \cdot C b \cdot C d h 1 a+k_{2 b c d h 1} \cdot C d h 1 C b-k_{d d C b} \cdot C b\right) \cdot e p s$

$\frac{d M b i}{d t}=\left(k_{\text {com } 4} \cdot C b \cdot\left(C d k 1_{t o t}-(M b i+M b+M b p 27+M b W e e 1+M b i P b\right.\right.$

$+M b P b i+M b C d c 20 i+M b C d h 1))-k_{\text {decom } 4} \cdot M b i+k_{1 i} \cdot M b W e e 1-k_{1 M b i} \cdot M b i \cdot P b$

$\left.+k_{2 M b i} \cdot M b i P b\right) \cdot e p s$

$\frac{d M b}{d t}=\left(k_{1 a} \cdot M b i P b-k_{c 7} \cdot M b \cdot p 27+k_{c 8} \cdot M b p 27-k_{1 c d h 1 b} \cdot C d h 1 a \cdot M b\right.$

$+k_{2 c d h 1 b} \cdot M b C d h 1+k_{i c d h 1 b} \cdot M b C d h 1-k_{1 M b} \cdot M b \cdot W e e 1+k_{2 M b} \cdot M b W e e 1$

[63]

$-k_{1 P b i} \cdot M b \cdot P b i+k_{2 a} \cdot M b P b i+k_{2 P b i} \cdot M b P b i+k_{3 a} \cdot M b C d c 20 i$

$\left.-k_{1 c d c 20 i} \cdot C d c 20 i \cdot M b+k_{2 c d c 20 i} \cdot M b C d c 20 i\right) \cdot e p s$

$\frac{d M b p 27}{d t}=\left(k_{c 7} \cdot M b \cdot p 27-k_{c 8} \cdot M b p 27\right) \cdot e p s$

$\frac{d W e e 1}{d t}=\left(k_{\text {swee } 1}-k_{1 M b} \cdot M b \cdot W e e 1+k_{2 M b} \cdot M b W e e 1+k_{1 a w} \cdot\right.$ PhosWeel

$-k_{1 \text { maweel }} \cdot M a \cdot$ Weel $+k_{2 \text { maweel }} \cdot$ MaWeel $+k_{\text {imaweel }} \cdot$ MaWee1 $-k_{1 \text { meweel }} \cdot$ Me Weel

$+k_{2 \text { meweel }} \cdot M e W e e 1+k_{\text {imeweel }} \cdot M e W e e 1-k_{d d W e e 1} \cdot$ Weel $) \cdot$ eps

$\frac{d W e e 1 p}{d t}=\left(k_{1 i} \cdot M b W e e 1+k_{2 w p} \cdot\right.$ PhosWee1 $-k_{1 w p} \cdot$ Weel $p \cdot\left(\right.$ Phosl $1_{t o t}-$ PhosWeel $)$

$-k_{d d W e e 1 p} \cdot$ Weel $\left.p\right) \cdot e p s$

$\frac{d P h o s 1}{d t}=\left(k_{2 w p} \cdot\right.$ PhosWee1 $-k_{1 w p} \cdot$ Weel $p \cdot\left(\right.$ Phosl $1_{t o t}-$ Phos Weel $)$

$+k_{\text {law }} \cdot$ PhosWeel) $\cdot$ eps

$\frac{d P h o s W e e 1}{d t}=\left(k_{1 w p} \cdot\right.$ Weel $p \cdot\left(\right.$ Phos $1_{t o t}-$ PhosWee1 $)-k_{2 w p} \cdot$ PhosWee1 - $k_{1 a w} \cdot$ PhosWeel) eps 
$\frac{d M b W e e 1}{d t}=\left(k_{1 M b} \cdot M b \cdot W e e 1-k_{2 M b} \cdot M b W e e 1-k_{1 i} \cdot M b W e e 1\right) \cdot e p s$

$\frac{d P b}{d t}=\left(k_{2 M b i} \cdot M b i P b-k_{1 M b i} \cdot M b i \cdot P b+k_{1 a} \cdot M b i P b+k_{2 a} \cdot M b P b i-k_{d d P b} \cdot P b\right) \cdot e p s$

$\frac{d P b i}{d t}=\left(k_{s P b i}-k_{1 P b i} \cdot M b \cdot P b i+k_{2 P b i} \cdot M b P b i-k_{d d P b i} \cdot P b i\right) \cdot e p s$

$\frac{d M b i P b}{d t}=\left(k_{1 M b i} \cdot M b i \cdot P b-k_{2 M b i} \cdot M b i P b-k_{1 a} \cdot M b i P b\right) \cdot e p s$

$\frac{d M b P b i}{d t}=\left(k_{1 P b i} \cdot M b \cdot P b i-k_{2 P b i} \cdot M b P b i-k_{2 a} \cdot M b P b i\right) \cdot e p s$

$\frac{d C d c 20 i}{d t}=\left(k_{s c d c 20 i}+k 2 c d c 20 i \cdot M b C d c 20 i-k_{1 c d c 20 i} \cdot C d c 20 i \cdot M b\right.$

$\left.+k_{1 i 20} \cdot \operatorname{Phos} C d c 20-k_{d d C d c 20 i} \cdot C d c 20 i\right) \cdot e p s$

$\frac{d C d c 20}{d t}=\left(k_{3 a} \cdot M b C d c 20 i-k_{1 b c d c 20} \cdot C d c 20 \cdot C b+k_{2 b c d c 20} \cdot C d c 20 C b\right.$

$-k_{1 a c d c 20} \cdot C d c 20 \cdot C a+k_{2 a c d c 20} \cdot C d c 20 C a+k_{1 d} \cdot C d c 20 C b+k_{2 d} \cdot C d c 20 C a$

$+k_{2 c p 2} \cdot \operatorname{Phos} C d c 20-k_{1 c p 2} \cdot C d c 20 \cdot\left(P h o s 2_{\text {tot }}-\right.$ PhosCdc20)- $\left.k_{d d c d c 20} \cdot C d c 20\right) \cdot$ eps

$\frac{d P h o s 2}{d t}=\left(k_{2 c p 2} \cdot P h o s C d c 20-k_{1 c p 2} \cdot C d c 20 \cdot\left(P_{h o s}{ }_{t o t}-P h o s C d c 20\right)\right.$

- $k_{1 i 20} \cdot$ PhosCdc20) $\cdot$ eps

[76]

$\frac{d P h o s C d c 20}{d t}=\left(k_{1 c p 2} \cdot C d c 20 \cdot\left(P h o s 2_{t o t}-P h o s C d c 20\right)-k_{2 c p 2} \cdot \operatorname{Phos} C d c 20\right.$

$-k_{1 i 20} \cdot$ Phos Cdc20) $\cdot$ eps

$\frac{d M b C d c 20 i}{d t}=\left(k_{1 c d c 20 i} \cdot C d c 20 i \cdot M b-k_{2 c d c 20 i} \cdot M b C d c 20 i-k_{3 a} \cdot M b C d c 20 i\right) \cdot e p s$

$\frac{d C d c 20 C b}{d t}=\left(k_{1 b c d c 20} \cdot C d c 20 \cdot C b-k_{2 b c d c 20} \cdot C d c 20 C b-k_{1 d} \cdot C d c 20 C b\right.$

$\left.-k_{d d 2} \cdot C d c 20 C b\right) \cdot e p s$

$\frac{d C b u}{d t}=\left(k_{1 d} \cdot C d c 20 C b+k_{3 d} \cdot C d h 1 C b-k_{d C b u} \cdot C b u-k_{d d C b u} \cdot C b u\right) \cdot e p s$

[80]

The Table 2 is a list of all variables involved in the model for the Cdk network, which counts 80 variables, and which is only based on mass-action kinetics. 
Table 2: Variables of the 80-variable model for the Cdk network based on mass-action kinetics

\begin{tabular}{|c|c|c|}
\hline Eqs. & $\underline{\text { Symbol }}$ & Definition \\
\hline 1 & $A P 1$ & Transcription factor $A P l$ \\
\hline 2 & $p R B$ & Unphosphorylated retinoblastoma protein \\
\hline 3 & $p R B c 1$ & Complex between $p R B$ and $E 2 F$ \\
\hline 4 & $p R B p$ & Retinoblastoma protein phosphorylated once \\
\hline 5 & $p R B c 2$ & Complex between $p R B p$ and $E 2 F$ \\
\hline 6 & $p R B p p$ & Retinoblastoma protein phosphorylated twice \\
\hline 7 & $E 2 F$ & Transcription factor $E 2 F$ \\
\hline 8 & $E 2 F u$ & Phosphorylated form of $E 2 F$ \\
\hline 9 & $E 2 F M a$ & Complex between $E 2 F$ and cyclin A/Cdk2 $(M a)$ \\
\hline 10 & $M d p R B$ & Complex between cyclin D/Cdk4-6 $(M d)$ and $p R B$ \\
\hline 11 & $M d p 27 p R B$ & Complex between cyclin D/Cdk4-6/p27 (Mdp27) and $p R B$ \\
\hline 12 & $M e p R B p$ & Complex between cyclin E/Cdk2 $(M e)$ and $p R B p$ \\
\hline 13 & $C d$ & Cyclin D protein \\
\hline 14 & Mdi & Inactive complex cyclin D/Cdk4-6 \\
\hline 15 & $M d$ & Active complex cyclin D/Cdk4-6 \\
\hline 16 & Mdp27 & Active complex between cyclin D/Cdk4-6 and $p 27$ \\
\hline 17 & $M d P d$ & $\begin{array}{l}\text { Complex between active form of cyclin D/Cdk4-6 }(M d) \text { and the phosphatase } \\
\text { leading to its inactivation }(P d)\end{array}$ \\
\hline 18 & $P d$ & Active form of phosphatase acting on cyclin D/Cdk4-6 \\
\hline 19 & kin1 & Active form of an unspecified kinase acting on cyclin D/Cdk4-6 \\
\hline 20 & kin1Mdi & $\begin{array}{c}\text { Complex between inactive form of cyclin D/Cdk4-6 (Mdi) and the kinase } \\
\text { leading to its activation }(\text { kinl) }\end{array}$ \\
\hline 21 & $\mathrm{Ce}$ & Cyclin E protein \\
\hline 22 & $\mathrm{Mei}$ & Inactive complex cyclin $\mathrm{E} / \mathrm{Cdk} 2$ \\
\hline 23 & $M e$ & Active complex cycline E/Cdk2 \\
\hline 24 & $P e i$ & Inactive form of phosphatase $\mathrm{Cdc} 25$ acting on cyclin $\mathrm{E} / \mathrm{Cdk} 2$ \\
\hline 25 & $\mathrm{MePei}$ & $\begin{array}{l}\text { Complex between active form of cyclin E/Cdk2 (enzyme) and the inactive } \\
\text { form of phosphatase (Pei), which is activated through phosphorylation by } \\
\text { cyclin E/Cdk2 }\end{array}$ \\
\hline 26 & $P e$ & $\begin{array}{l}\text { Active form of phosphatase } \mathrm{Cdc} 25(\mathrm{Pe}) \text { leading to the activation of cyclin } \\
\text { E/Cdk2 by dephosphorylation }\end{array}$ \\
\hline 27 & Mep27 & Inactive complex between cyclin E/Cdk2 and $p 27$ \\
\hline 28 & Skp2 & Skp2 protein \\
\hline 29 & CeSkp2 & Complex between cyclin E and $S k p 2$ \\
\hline 30 & $\mathrm{Ceu}$ & Ubiquitinated form of cyclin $\mathrm{E}$ \\
\hline 31 & Cdh1Skp2 & Complex between $C d h 1$ protein (enzyme) and $S k p 2$ (substrate) \\
\hline 32 & Skp2u & Ubiquitinated form of $S k p 2$ \\
\hline 33 & MeiPe & $\begin{array}{l}\text { Complex between the inactive form of cyclin } \mathrm{E} / \mathrm{Cdk} 2 \text { and the active form of } \\
\text { phosphatase } \mathrm{Pe}\end{array}$ \\
\hline 34 & kin2 & Unspecified kinase leading to the inactivation of cyclin E/Cdk2 \\
\hline 35 & kin2Me & $\begin{array}{l}\text { Complex between the kinase (kin2) leading to the inactivation of cyclin } \\
\text { E/Cdk2 and the active form of cyclin E/Cdk2 }\end{array}$ \\
\hline
\end{tabular}




\begin{tabular}{|c|c|c|}
\hline 36 & MeWeel & $\begin{array}{c}\text { Complex between cyclin E/Cdk2 and the kinase Wee1 also leading to the } \\
\text { inactivation of cyclin E/Cdk2 }\end{array}$ \\
\hline 37 & $\mathrm{Ca}$ & Cyclin A \\
\hline 38 & Mai & Inactive cyclin $\mathrm{A} / \mathrm{Cdk} 2$ complex \\
\hline 39 & $M a$ & Active cyclin $\mathrm{A} / \mathrm{Cdk} 2$ complex \\
\hline 40 & $p 27$ & Protein inhibitor p27 (or p21) \\
\hline 41 & $p 27 p$ & Inactive, phosphorylated, form of p27 \\
\hline 42 & $p 27 p S k p 2$ & Complex between the phosphorylated form of p27 and Skp2 \\
\hline 43 & $p 27 u$ & Ubiquitinated form of p27 \\
\hline 44 & Map27 & Inactive complex between cyclin A/Cdk2 and p27 \\
\hline 45 & Cdhli & Inactive form of Cdh1 protein \\
\hline 46 & Cdhla & Active form of Cdh1 protein \\
\hline 47 & $M b C d h 1$ & $\begin{array}{l}\text { Complex between the active form of Cdh1 (substrate) and the cyclin } \\
\text { B/Cdk1 (enzyme) which ensures the inactivation of Cdh1 by } \\
\text { phosphorylation }\end{array}$ \\
\hline 48 & Phos3 & $\begin{array}{l}\text { Unspecified phosphatase leading to the activation, by dephosphorylation, of } \\
\text { the protein Cdh1 }\end{array}$ \\
\hline 49 & PhosCdhl & $\begin{array}{c}\text { Complex between the phophatase leading to the activation of Cdh1 and the } \\
\text { inactive form of Cdh1 }\end{array}$ \\
\hline 50 & $P a i$ & $\begin{array}{l}\text { Inactive form of the phosphatase Cdc25 leading to the activation of cyclin } \\
\qquad \mathrm{A} / \mathrm{Cdk} 2\end{array}$ \\
\hline 51 & $P a$ & $\begin{array}{l}\text { Active form of the phosphatase } \mathrm{Cdc} 25 \text { leading to the activation of cyclin } \\
\qquad \mathrm{A} / \mathrm{Cdk} 2\end{array}$ \\
\hline 52 & $\mathrm{MaiPa}$ & $\begin{array}{l}\text { Complex between the inactive form of cyclin } \mathrm{A} / \mathrm{Cdk} 2 \text { and the active form of } \\
\text { phosphatase } \mathrm{Pa}\end{array}$ \\
\hline 53 & MaPai & $\begin{array}{l}\text { Complex between the active form of cyclin } \mathrm{A} / \mathrm{Cdk} 2 \text { (enzyme) and the } \\
\text { inactive form of phosphatase (Pai), which is activated by phosphorylation } \\
\text { by cyclin } \mathrm{A} / \mathrm{Cdk} 2\end{array}$ \\
\hline 54 & $M a C d h 1$ & $\begin{array}{l}\text { Complex between the active form of Cdh1 (substrat) and the cyclin A/Cdk2 } \\
\text { (enzyme), which ensures the inactivation of Cdh1 by phosphorylation }\end{array}$ \\
\hline 55 & $C d c 20 C a$ & $\begin{array}{c}\text { Complex between cyclin A (substrate) and the Cdc20 protein (enzyme), } \\
\text { which ensures the degradation of cyclin A }\end{array}$ \\
\hline 56 & $C d h 1 C b$ & $\begin{array}{c}\text { Complex between cyclin B (substrate) and the Cdh1 protein (enzyme) which } \\
\text { promotes the degradation of cyclin B }\end{array}$ \\
\hline 57 & $\mathrm{Cau}$ & Ubiquitinated form of cyclin A \\
\hline 58 & kin3 & Unspecified kinase leading to the inactivation of cyclin $\mathrm{A} / \mathrm{Cdk} 2$ \\
\hline 59 & kin $3 M a$ & $\begin{array}{l}\text { Complex between cyclin } \mathrm{A} / \mathrm{Cdk} 2 \text { (substrate) and the kinase kin3 (enzyme) } \\
\text { promoting the inactivation of cyclin } \mathrm{A} / \mathrm{Cdk} 2 \text { by phosphorylation }\end{array}$ \\
\hline 60 & MaWeel & $\begin{array}{l}\text { Complex between cyclin } \mathrm{A} / \mathrm{Cdk} 2 \text { (substrate) and the kinase Weel (enzyme), } \\
\text { which also inactivates cyclin } \mathrm{A} / \mathrm{Cdk} 2 \text { by phosphorylation }\end{array}$ \\
\hline 61 & $\mathrm{Cb}$ & Cyclin B \\
\hline 62 & $M b i$ & Inactive complex cyclin $\mathrm{B} / \mathrm{Cdk} 1$ \\
\hline 63 & $M b$ & Active complex cyclin B/Cdk1 \\
\hline 64 & Mbp27 & Inactive complex between cyclin B/Cdk1 and p27 \\
\hline 65 & Weel & Kinase Wee1 \\
\hline 66 & Weelp & Inactive, phosphorylated, form of the kinase Wee1 \\
\hline
\end{tabular}




\begin{tabular}{|c|c|c|}
\hline 67 & Phosl & $\begin{array}{c}\text { Unspecified phosphatase leading to the activation of kinase Wee1 by } \\
\text { dephosphorylation }\end{array}$ \\
\hline 68 & PhosWeel & $\begin{array}{c}\text { Complex between the phosphatase leading to the activation of Wee1 and the } \\
\text { inactive form of Wee1 }\end{array}$ \\
\hline 69 & MbWeel & Complex between cyclin B/Cdk1 and the kinase Wee1 \\
\hline 70 & $\mathrm{~Pb}$ & $\begin{array}{l}\text { Active form of the phosphatase } \mathrm{Cdc} 25 \text { leading to the activation of cyclin } \\
\qquad \mathrm{B} / \mathrm{Cdk} 1\end{array}$ \\
\hline 71 & $P b i$ & $\begin{array}{l}\text { Inactive form of the phosphatase Cdc25 leading to the activation of cyclin } \\
\qquad \mathrm{B} / \mathrm{Cdk} 1\end{array}$ \\
\hline 72 & $\mathrm{MbiPb}$ & $\begin{array}{l}\text { Complex between the inactive form of cyclin } \mathrm{B} / \mathrm{Cdk} 1 \text { and the active form of } \\
\text { phosphatase } \mathrm{Pb}\end{array}$ \\
\hline 73 & $M b P b i$ & $\begin{array}{c}\text { Complex between the active form of cyclin B/Cdk1 (enzyme) and the } \\
\text { inactive form of phosphatase (Pbi), which is activated through } \\
\text { phosphorylation by cyclin B/Cdk1 }\end{array}$ \\
\hline 74 & $C d c 20 i$ & Inactive form of $\mathrm{Cdc} 20$ protein \\
\hline 75 & Cdc20 & Active form of Cdc20 protein \\
\hline 76 & Phos2 & $\begin{array}{l}\text { Unspecified phosphatase promoting the inactivation, by dephosphorylation, } \\
\text { of Cdc } 20 \text { protein }\end{array}$ \\
\hline 77 & PhosCdc20 & Complex between the phosphatase Phos2 (enzyme) and Cdc20 (substrate) \\
\hline 78 & $M b C d c 20 i$ & $\begin{array}{c}\text { Complex between cyclin B/Cdk1 (enzyme) and the inactive form of Cdc20 } \\
\text { (substrate) }\end{array}$ \\
\hline 79 & $C d c 20 C b$ & Complex between cyclin B (substrate) and Cdc20 (enzyme) \\
\hline 80 & $\mathrm{Cbu}$ & Ubiquitinated form of cyclin B \\
\hline
\end{tabular}

The Table 3 defines all the parameters of the 80 -variable model and gives a list of their numerical values used in the simulations.

Table 3: Parameters of the model

\begin{tabular}{|c|c|c|}
\hline$\underline{\text { Symbol }}$ & Definition & $\begin{array}{l}\text { Numerical } \\
\text { value }\end{array}$ \\
\hline \multicolumn{3}{|c|}{ Mitotic stimulation by growth factor, $G F$} \\
\hline$G F$ & Growth factor & $1 \mu \mathrm{M}$ \\
\hline$V_{\text {sap1 }}$ & $\begin{array}{l}\text { Rate of synthesis of the transcription factor AP1 depending of } \\
\text { the growth factor GF }\end{array}$ & $0.08 \mu \mathrm{Mh}^{-1}$ \\
\hline$K_{\text {agf }}$ & $\begin{array}{l}\text { Michaelis constant for synthesis of AP1 induced by growth } \\
\text { factor GF }\end{array}$ & $1 \mu \mathrm{M}$ \\
\hline$k_{\text {dap1 }}$ & $\begin{array}{c}\text { Apparent first-order rate constant for AP1 transcription factor } \\
\text { degradation }\end{array}$ & $2 \mathrm{~h}^{-1}$ \\
\hline eps & Scaling factor used to modify the time scale & 600 \\
\hline \multicolumn{3}{|c|}{ Antagonistic regulation exerted by $p R B$ and $E 2 F$} \\
\hline$k_{\text {ade2f }}$ & $\begin{array}{l}\text { Apparent first-order rate constant for the phosphorylation of E2F } \\
\text { induced by cyclin A/Cdk2 }\end{array}$ & $0.3 \mathrm{~h}^{-1}$ \\
\hline$k_{\mathrm{ddd} 2 \mathrm{f}}$ & $\begin{array}{l}\text { Apparent first-order rate constant for non-specific degradation of } \\
\text { E2F }\end{array}$ & $0.02 \mathrm{~h}^{-1}$ \\
\hline
\end{tabular}




\begin{tabular}{|c|c|c|}
\hline$k_{\text {dde2fu }}$ & $\begin{array}{l}\text { Apparent first-order rate constant for non-specific E2Fu } \\
\text { degradation }\end{array}$ & $0.005 \mathrm{~h}^{-1}$ \\
\hline$k_{\mathrm{de} 2 \mathrm{fu}}$ & Apparent first-order rate constant for E2Fu degradation & $0.1 \mathrm{~h}^{-1}$ \\
\hline$k_{\mathrm{ddpRB}}$ & $\begin{array}{l}\text { Apparent first-order rate constant for non-specific pRB } \\
\text { degradation }\end{array}$ & $0.05 \mathrm{~h}^{-1}$ \\
\hline$k_{\mathrm{ddpRBp}}$ & $\begin{array}{l}\text { Apparent first-order rate constant for non-specific pRBp } \\
\text { degradation }\end{array}$ & $0.05 \mathrm{~h}^{-1}$ \\
\hline$k_{\mathrm{ddpRBpp}}$ & $\begin{array}{l}\text { Apparent first-order rate constant for non-specific pRBpp } \\
\text { degradation }\end{array}$ & $0.02 \mathrm{~h}^{-1}$ \\
\hline$k_{\mathrm{ilpRB}}$ & $\begin{array}{l}\text { Apparent first-order rate constant for phosphorylation of pRB by } \\
\text { cyclin D/Cdk4-6 }\end{array}$ & $0.3 \mathrm{~h}^{-1}$ \\
\hline$k_{\mathrm{i} 2 \mathrm{pRB}}$ & $\begin{array}{l}\text { Apparent first-order rate constant for phosphorylation of pRB by } \\
\text { cyclin D/Cdk4-6/p27 }\end{array}$ & $0.3 \mathrm{~h}^{-1}$ \\
\hline$k_{\mathrm{i} 3 \mathrm{pRB}}$ & $\begin{array}{l}\text { Apparent first-order rate constant for phosphorylation of pRBp } \\
\text { by cyclin } E / C d k 2\end{array}$ & $0.05 \mathrm{~h}^{-1}$ \\
\hline$k_{\mathrm{pcl} 1}$ & Bimolecular rate constant for binding of $\mathrm{pRB}$ to $\mathrm{E} 2 \mathrm{~F}$ & $0.05 \mu \mathrm{M}^{-1} \mathrm{~h}^{-1}$ \\
\hline$k_{\mathrm{pc} 2}$ & Rate constant for dissociation of complex between $\mathrm{pRB}$ and E2F & $0.5 \mathrm{~h}^{-1}$ \\
\hline$k_{\mathrm{pc} 3}$ & Bimolecular rate constant for binding of $\mathrm{pRBp}$ to $\mathrm{E} 2 \mathrm{~F}$ & $0.025 \mu \mathrm{M}^{-1} \mathrm{~h}^{-1}$ \\
\hline$k_{\mathrm{pc} 4}$ & $\begin{array}{l}\text { Rate constant for dissociation of complex between } \mathrm{pRBp} \text { and } \\
\qquad \text { E2F }\end{array}$ & $0.5 \mathrm{~h}^{-1}$ \\
\hline$k_{1 \mathrm{e2f}}$ & Bimolecular rate constant for binding of cyclin $\mathrm{A} / \mathrm{Cdk} 2$ to $\mathrm{E} 2 \mathrm{~F}$ & $200 \mu \mathrm{M}^{-1} \mathrm{~h}^{-1}$ \\
\hline$k_{2 \mathrm{e} 2 \mathrm{f}}$ & $\begin{array}{l}\text { Rate constant for dissociation of complex between cyclin } \\
\qquad \mathrm{A} / \mathrm{Cdk} 2 \text { and } \mathrm{E} 2 \mathrm{~F}\end{array}$ & $120 \mathrm{~h}^{-1}$ \\
\hline$k_{\mathrm{lpRB}}$ & Bimolecular rate constant for binding of $\mathrm{pRB}$ to cyclin $\mathrm{D} / \mathrm{Cdk} 4-6$ & $4 \mu \mathrm{M}^{-1} \mathrm{~h}^{-1}$ \\
\hline$k_{2 \mathrm{pRB}}$ & $\begin{array}{l}\text { Rate constant for dissociation of complex between } \mathrm{pRB} \text { and } \\
\text { cyclin D/Cdk4-6 }\end{array}$ & $2 \mathrm{~h}^{-1}$ \\
\hline$k_{3 \mathrm{pRB}}$ & $\begin{array}{l}\text { Bimolecular rate constant for binding of pRB to cyclin D/Cdk4- } \\
\qquad 6 / \mathrm{p} 27\end{array}$ & $6 \mu \mathrm{M}^{-1} \mathrm{~h}^{-1}$ \\
\hline$k_{4 \mathrm{pRB}}$ & $\begin{array}{l}\text { Rate constant for dissociation of complex between } \mathrm{pRB} \text { and } \\
\text { cyclin } \mathrm{D} / \mathrm{Cdk} 4-6 / \mathrm{p} 27\end{array}$ & $3 \mathrm{~h}^{-1}$ \\
\hline$k_{1 \mathrm{pRBp}}$ & Bimolecular rate constant for binding of pRBp to cyclin $\mathrm{E} / \mathrm{Cdk} 2$ & $0.5 \mu \mathrm{M}^{-1} \mathrm{~h}^{-1}$ \\
\hline$k_{2 \mathrm{pRBp}}$ & $\begin{array}{l}\text { Rate constant for dissociation of complex between pRBp and } \\
\text { cyclin E/Cdk2 }\end{array}$ & $10 \mathrm{~h}^{-1}$ \\
\hline 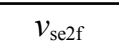 & Rate of synthesis of E2F & $0.08 \mu \mathrm{Mh}^{-1}$ \\
\hline$v_{\mathrm{spRB}}$ & Rate of synthesis of $\mathrm{pRB}$ & $1 \mu \mathrm{Mh}^{-1}$ \\
\hline \multicolumn{3}{|c|}{ Module Cyclin D/Cdk4-6 : G1 phase } \\
\hline$C d k 4_{\text {tot }}$ & Total concentration of the Cdk4-6 kinase & $4.3 \mu \mathrm{M}$ \\
\hline$k_{\mathrm{cl} 1}$ & Bimolecular rate constant for binding of cyclin D/Cdk4-6 to p27 & $1 \mu \mathrm{M}^{-1} \mathrm{~h}^{-1}$ \\
\hline$k_{\mathrm{c} 2}$ & $\begin{array}{l}\text { Rate constant for dissociation of complex between cyclin } \\
\qquad \mathrm{D} / \mathrm{Cdk} 4-6 \text { and } \mathrm{p} 27\end{array}$ & $0.1 \mathrm{~h}^{-1}$ \\
\hline$k_{\mathrm{cd} 1}$ & Rate constant for cyclin D synthesis induced by AP1 & $0.5 \mathrm{~h}^{-1}$ \\
\hline$k_{\mathrm{cd} 2}$ & Rate constant for cyclin D synthesis regulated by E2F and pRB & $0.001 \mathrm{~h}^{-1}$ \\
\hline$k_{\mathrm{ddCd}}$ & Apparent first-order rate constant for cyclin D degradation & $0.1 \mathrm{~h}^{-1}$ \\
\hline$k_{\text {decom1 }}$ & $\begin{array}{l}\text { Rate constant for dissociation of complex between cyclin D and } \\
\text { kinase Cdk4-6 }\end{array}$ & $0.1 \mathrm{~h}^{-1}$ \\
\hline
\end{tabular}




\begin{tabular}{|c|c|c|}
\hline$k_{\mathrm{com} 1}$ & $\begin{array}{l}\text { Bimolecular rate constant for binding of cyclin D to kinase } \\
\qquad \text { Cdk4-6 }\end{array}$ & $0.4 \mu \mathrm{M}^{-1} \mathrm{~h}^{-1}$ \\
\hline$K_{\mathrm{i} 7}$ & Constant of inhibition by pRB of cyclin D synthesis & $0.1 \mu \mathrm{M}$ \\
\hline$K_{\mathrm{i} 8}$ & Constant of inhibition by pRBp of cyclin D synthesis & $2 \mu \mathrm{M}$ \\
\hline$k_{\text {lad }}$ & $\begin{array}{l}\text { Apparent first-order rate constant for activation of cyclin } \\
\text { D/Cdk4-6 by the kinase kin 1 }\end{array}$ & $0.07 \mathrm{~h}^{-1}$ \\
\hline$k_{\text {lid }}$ & $\begin{array}{l}\text { Apparent first-order rate constant for inactivation of cyclin } \\
\text { D/Cdk4-6 by the phosphatase } P d\end{array}$ & $0.1 \mathrm{~h}^{-1}$ \\
\hline$k_{1 \mathrm{Md}}$ & $\begin{array}{l}\text { Bimolecular rate constant for binding of active form of cyclin } \\
\text { D/Cdk4-6 to phosphatase } P d\end{array}$ & $2.5 \mu \mathrm{M}^{-1} \mathrm{~h}^{-1}$ \\
\hline$k_{2 \mathrm{Md}}$ & $\begin{array}{l}\text { Rate constant for dissociation of complex between active form of } \\
\text { cyclin D/Cdk4-6 and phosphatase } P d\end{array}$ & $1.2 \mathrm{~h}^{-1}$ \\
\hline$k_{1 \mathrm{Mdi}}$ & $\begin{array}{l}\text { Bimolecular rate constant for binding of inactive form of cyclin } \\
\qquad \mathrm{D} / \mathrm{Cdk} 4-6 \text { to kinase kin 1 }\end{array}$ & $7 \mu \mathrm{M}^{-1} \mathrm{~h}^{-1}$ \\
\hline$k_{2 \mathrm{Mdi}}$ & $\begin{array}{l}\text { Rate constant for dissociation of complex between inactive form } \\
\text { of cyclin D/Cdk4-6 and kinase kin } 1\end{array}$ & $2 \mathrm{~h}^{-1}$ \\
\hline$k i n 1_{\text {tot }}$ & Total concentration of kinase $k$ in 1 & $0.02 \mu \mathrm{M}$ \\
\hline$P d_{\text {tot }}$ & Total concentration of phosphatase $P d$ & $0.02 \mu \mathrm{M}$ \\
\hline \multicolumn{3}{|c|}{ Module Cyclin E/Cdk2 : G1 phase and G1/S transition } \\
\hline$k_{\mathrm{ce} 1}$ & Rate of synthesis of cyclin E & 0 \\
\hline$k_{\mathrm{ce} 2}$ & $\begin{array}{l}\text { Apparent first-order rate constant for cyclin E synthesis induced } \\
\text { by E2F }\end{array}$ & $0.3 \mathrm{~h}^{-1}$ \\
\hline$k_{\mathrm{c} 3}$ & Bimolecular rate constant for binding of cyclin E/Cdk2 to p27 & $0.3 \mu \mathrm{M}^{-1} \mathrm{~h}^{-1}$ \\
\hline$k_{\mathrm{c} 4}$ & $\begin{array}{l}\text { Rate constant for dissociation of complex between cyclin } \\
\text { E/Cdk2 and p27 }\end{array}$ & $0.2 \mathrm{~h}^{-1}$ \\
\hline$k_{\text {com2 }}$ & Bimolecular rate constant for binding of cyclin E to kinase Cdk2 & $0.125 \mu \mathrm{M}^{-1} \mathrm{~h}^{-1}$ \\
\hline$k_{\text {decom2 }}$ & $\begin{array}{l}\text { Rate constant for dissociation of complex between cyclin E to } \\
\text { kinase Cdk2 }\end{array}$ & $0.1 \mathrm{~h}^{-1}$ \\
\hline$k_{\mathrm{ddCe}}$ & $\begin{array}{l}\text { Apparent first-order rate constant for non-specific degradation of } \\
\text { cyclin E }\end{array}$ & $0.05 \mathrm{~h}^{-1}$ \\
\hline$k_{\mathrm{dCeu}}$ & $\begin{array}{l}\text { Apparent first-order rate constant for degradation of } \\
\text { ubiquitinated form of cyclin E }\end{array}$ & $0.05 \mathrm{~h}^{-1}$ \\
\hline$k_{\mathrm{ddCeu}}$ & $\begin{array}{l}\text { Apparent first-order rate constant for non-specific degradation of } \\
\text { ubiquitinated form of cyclin E }\end{array}$ & $0.001 \mathrm{~h}^{-1}$ \\
\hline$k_{\mathrm{ddPe}}$ & $\begin{array}{c}\text { Apparent first-order rate constant for non-specific degradation of } \\
\text { active form of phosphatase } P e\end{array}$ & $0.05 \mathrm{~h}^{-1}$ \\
\hline$k_{\mathrm{ddPei}}$ & $\begin{array}{c}\text { Apparent first-order rate constant for non-specific degradation of } \\
\text { inactive form of phosphatase } \mathrm{Pei}\end{array}$ & $0.0075 \mathrm{~h}^{-1}$ \\
\hline$k_{\mathrm{dSkp} 2 \mathrm{u}}$ & $\begin{array}{l}\text { Apparent first-order rate constant for degradation of } \\
\text { ubiquitinated form of Skp2 }\end{array}$ & $0.05 \mathrm{~h}^{-1}$ \\
\hline$k_{\mathrm{ddSkp2}}$ & $\begin{array}{l}\text { Apparent first-order rate constant for non-specific degradation of } \\
\text { Skp2 }\end{array}$ & $0.005 \mathrm{~h}^{-1}$ \\
\hline$k_{\mathrm{ddSkp2u}}$ & $\begin{array}{c}\text { Apparent first-order rate constant for non-specific degradation of } \\
\text { ubiquitinated form of Skp2 }\end{array}$ & $0.001 \mathrm{~h}^{-1}$ \\
\hline$k_{\mathrm{dd} 6}$ & $\begin{array}{l}\text { Apparent first-order rate constant for non-specific degradation of } \\
\text { complex between cyclin E and Skp2 }\end{array}$ & $0.001 \mathrm{~h}^{-1}$ \\
\hline
\end{tabular}




\begin{tabular}{|c|c|c|}
\hline$k_{\mathrm{dd} 7}$ & $\begin{array}{l}\text { Apparent first-order rate constant for non-specific degradation of } \\
\text { complex between Cdh1 and Skp2 }\end{array}$ & $0.001 \mathrm{~h}^{-1}$ \\
\hline$k_{\text {imeweel }}$ & Constant of inhibition by the kinase Wee1 of cyclin E/Cdk2 & $0.02 \mathrm{~h}^{-1}$ \\
\hline$k_{s P e i}$ & Rate of synthesis of phosphatase $P e i$ & $0.02 \mu \mathrm{Mh}^{-1}$ \\
\hline$K_{\mathrm{i} 9}$ & Constant of inhibition by $\mathrm{pRB}$ of cyclin E synthesis & $0.1 \mu \mathrm{M}$ \\
\hline$K_{\mathrm{i} 10}$ & Constant of inhibition by pRBp of cyclin E synthesis & $2 \mu \mathrm{M}$ \\
\hline$k_{1 \text { meweel }}$ & $\begin{array}{l}\text { Bimolecular rate constant for binding of cyclin E/Cdk2 to the } \\
\text { kinase Wee1 }\end{array}$ & $0.2 \mu \mathrm{M}^{-1} \mathrm{~h}^{-1}$ \\
\hline$k_{2 \text { meweel }}$ & $\begin{array}{l}\text { Rate constant for dissociation of complex between cyclin } \\
\text { E/Cdk2 and kinase Weel }\end{array}$ & $5 \mathrm{~h}^{-1}$ \\
\hline$k_{\text {lie }}$ & Constant of inhibition by kinase kin2 of cyclin E/Cdk2 & $0.2 \mathrm{~h}^{-1}$ \\
\hline $\operatorname{kin} 2_{\text {tot }}$ & Total concentration of kinase kin2 & $0.02 \mu \mathrm{M}$ \\
\hline$k_{4 \mathrm{~d}}$ & $\begin{array}{l}\text { Apparent first-order rate constant for degradation of cyclin E } \\
\text { induced by Skp2 }\end{array}$ & $0.1 \mathrm{~h}^{-1}$ \\
\hline$k_{5 \mathrm{~d}}$ & $\begin{array}{l}\text { Apparent first-order rate constant for degradation of Skp2 } \\
\text { induced by Cdh1 }\end{array}$ & $0.01 \mathrm{~h}^{-1}$ \\
\hline$k_{\text {lae }}$ & $\begin{array}{c}\text { Apparent first-order rate constant for activation of cyclin E/Cdk2 } \\
\text { by phosphatase Cdc25 Pe }\end{array}$ & $0.06 \mathrm{~h}^{-1}$ \\
\hline$k_{\text {2a }}$ & $\begin{array}{l}\text { Apparent first-order rate constant for activation of phosphatase } \\
\qquad \mathrm{Cdc} 25 \mathrm{Pe} \text { by cyclin E/Cdk2 }\end{array}$ & $0.05 \mathrm{~h}^{-1}$ \\
\hline$k_{\text {leskp2 }}$ & Bimolecular rate constant for binding of cyclin E to Skp2 & $3.5 \mu \mathrm{M}^{-1} \mathrm{~h}^{-1}$ \\
\hline$k_{\text {2eskp2 }}$ & $\begin{array}{l}\text { Rate constant for dissociation of complex between cyclin E and } \\
\qquad \text { Skp2 }\end{array}$ & $1 \mathrm{~h}^{-1}$ \\
\hline$k_{1 \mathrm{Me}}$ & $\begin{array}{l}\text { Bimolecular rate constant for binding of cyclin } \mathrm{E} / \mathrm{Cdk} 2 \text { to the } \\
\text { kinase kin2 }\end{array}$ & $3 \mu \mathrm{M}^{-1} \mathrm{~h}^{-1}$ \\
\hline$k_{2 \mathrm{Me}}$ & $\begin{array}{l}\text { Rate constant for dissociation of complex between cyclin } \\
\text { E/Cdk2 and kinase kin2 }\end{array}$ & $5 \mathrm{~h}^{-1}$ \\
\hline$k_{1 \mathrm{Mei}}$ & $\begin{array}{l}\text { Bimolecular rate constant for binding of inactive form of cyclin } \\
\text { E/Cdk2 to active form of phosphatase } \mathrm{Cdc} 25 \mathrm{Pe}\end{array}$ & $3 \mu \mathrm{M}^{-1} \mathrm{~h}^{-1}$ \\
\hline$k_{2 \mathrm{Mei}}$ & $\begin{array}{l}\text { Rate constant for dissociation of complex between inactive form } \\
\text { of cyclin E/Cdk2 and active form of phosphatase Cdc } 25 \mathrm{Pe}\end{array}$ & $2 \mathrm{~h}^{-1}$ \\
\hline$k_{1 \text { Pei }}$ & $\begin{array}{l}\text { Bimolecular rate constant for binding of active form of cyclin } \\
\text { E/Cdk2 to inactive form of phosphatase } \mathrm{Cdc} 25 \mathrm{Pei}\end{array}$ & $2.5 \mu \mathrm{M}^{-1} \mathrm{~h}^{-1}$ \\
\hline$k_{2 \mathrm{Pei}}$ & $\begin{array}{l}\text { Rate constant for dissociation of complex between active form of } \\
\text { cyclin E/Cdk2 and active form of phosphatase Cdc } 25 \mathrm{Pei}\end{array}$ & $1.25 \mathrm{~h}^{-1}$ \\
\hline$k_{\text {lecdh1 }}$ & Bimolecular rate constant for binding of Skp2 to Cdh1 & $1 \mu \mathrm{M}^{-1} \mathrm{~h}^{-1}$ \\
\hline$k_{\text {2ecdh1 }}$ & $\begin{array}{l}\text { Rate constant for dissociation of complex between Skp2 and } \\
\text { Cdh1 }\end{array}$ & $20 \mathrm{~h}^{-1}$ \\
\hline$v_{\text {sskp2 }}$ & Rate of synthesis of Skp2 protein & $0.035 \mu \mathrm{Mh}^{-1}$ \\
\hline \multicolumn{3}{|c|}{ Module Cyclin $A / C d k 2: S$ phase and $S / G 2$ transition } \\
\hline$k_{\text {cal }}$ & Rate of synthesis of cyclin A & 0 \\
\hline$k_{\text {ca2 }}$ & Rate constant for cyclin A synthesis induced by E2F & $1.5 \mathrm{~h}^{-1}$ \\
\hline$C d k 2_{\text {tot }}$ & Total concentration of kinase Cdk2 & $10 \mu \mathrm{M}$ \\
\hline$K_{\mathrm{i} 11}$ & Constant of inhibition by pRB of cyclin A & $0.1 \mu \mathrm{M}$ \\
\hline$K_{\mathrm{i} 12}$ & Constant of inhibition by pRBp of cyclin A & $2 \mu \mathrm{M}$ \\
\hline
\end{tabular}




\begin{tabular}{|c|c|c|}
\hline$K_{\mathrm{i} 13}$ & Constant of inhibition by pRB of p27 & $0.1 \mu \mathrm{M}$ \\
\hline$K_{\mathrm{i} 14}$ & Constant of inhibition by pRBp of p27 & $2 \mu \mathrm{M}$ \\
\hline$k_{\mathrm{com} 3}$ & Bimolecular rate constant for binding of cyclin A to kinase Cdk2 & $0.3 \mu \mathrm{M}^{-1} \mathrm{~h}^{-1}$ \\
\hline$k_{\text {decom3 }}$ & $\begin{array}{l}\text { Rate constant for dissociation of complex between cyclin A and } \\
\text { kinase Cdk2 }\end{array}$ & $0.1 \mathrm{~h}^{-1}$ \\
\hline$k_{\mathrm{ddCa}}$ & $\begin{array}{l}\text { Apparent first-order rate constant for non-specific degradation of } \\
\text { cyclin A }\end{array}$ & $0.05 \mathrm{~h}^{-1}$ \\
\hline$k_{\mathrm{dCau}}$ & $\begin{array}{c}\text { Apparent first-order rate constant for degradation of } \\
\text { ubiquitinated form of cyclin A }\end{array}$ & $0.1 \mathrm{~h}^{-1}$ \\
\hline$k_{\mathrm{ddCau}}$ & $\begin{array}{c}\text { Apparent first-order rate constant for non-specific degradation of } \\
\text { ubiquitinated form of cyclin A }\end{array}$ & $0.001 \mathrm{~h}^{-1}$ \\
\hline$k_{\mathrm{ddPa}}$ & $\begin{array}{c}\text { Apparent first-order rate constant for non-specific degradation of } \\
\text { active form of phosphatase Cdc25 } \mathrm{Pa}\end{array}$ & $0.04 \mathrm{~h}^{-1}$ \\
\hline$k_{\text {ddPai }}$ & $\begin{array}{c}\text { Apparent first-order rate constant for non-specific degradation of } \\
\text { inactive form of phosphatase Cdc25 Pai }\end{array}$ & $0.04 \mathrm{~h}^{-1}$ \\
\hline$k_{\mathrm{dd} 27}$ & $\begin{array}{l}\text { Apparent first-order rate constant for non-specific degradation of } \\
\qquad \text { p27 }\end{array}$ & $0.05 \mathrm{~h}^{-1}$ \\
\hline$k_{\mathrm{dp} 27 \mathrm{p}}$ & $\begin{array}{l}\text { Apparent first-order rate constant for degradation of } \\
\text { phosphorylated form of p } 27\end{array}$ & $0.1 \mathrm{~h}^{-1}$ \\
\hline$k_{\mathrm{dp} 27 \mathrm{u}}$ & $\begin{array}{c}\text { Apparent first-order rate constant for degradation of } \\
\text { ubiquitinated form of p } 27\end{array}$ & $0.1 \mathrm{~h}^{-1}$ \\
\hline$k_{\text {ddCdhla }}$ & $\begin{array}{l}\text { Apparent first-order rate constant for non-specific degradation of } \\
\text { active form of Cdh1 }\end{array}$ & $0.002 \mathrm{~h}^{-1}$ \\
\hline$k_{\mathrm{ddCdh} 1 \mathrm{i}}$ & $\begin{array}{c}\text { Apparent first-order rate constant for non-specific degradation of } \\
\text { inactive form of Cdh1 }\end{array}$ & $0.04 \mathrm{~h}^{-1}$ \\
\hline$k_{\mathrm{ip} 27}$ & $\begin{array}{l}\text { Apparent first-order rate constant for inhibition by cyclin } \\
\qquad \text { E/Cdk2 of p } 27\end{array}$ & $0.3 \mathrm{~h}^{-1}$ \\
\hline$k_{\text {imawee }}$ & $\begin{array}{l}\text { Apparent first-order rate constant for inhibition by kinase Wee } 1 \\
\text { of cyclin } \mathrm{A} / \mathrm{Cdk} 2\end{array}$ & $0.02 \mathrm{~h}^{-1}$ \\
\hline$k_{\mathrm{ddCdh} 1 \mathrm{Cb}}$ & $\begin{array}{l}\text { Apparent first-order rate constant for non-specific degradation of } \\
\text { complex between cyclin B and Cdh1 }\end{array}$ & $0.06 \mathrm{~h}^{-1}$ \\
\hline$k_{\text {spai }}$ & Rate of synthesis of phosphatase Cdc25 Pai & $0.035 \mu \mathrm{Mh}^{-1}$ \\
\hline$k_{\text {lacdc20 }}$ & 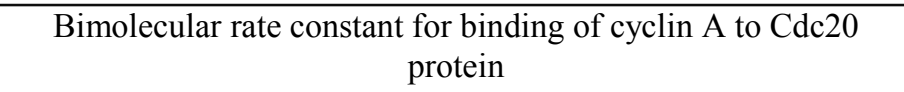 & $20 \mu \mathrm{M}^{-1} \mathrm{~h}^{-1}$ \\
\hline$k_{2 \text { addc20 }}$ & $\begin{array}{l}\text { Rate constant for dissociation of complex between cyclin A and } \\
\qquad \operatorname{Cdc} 20\end{array}$ & $12 \mathrm{~h}^{-1}$ \\
\hline$k_{\text {lMai }}$ & $\begin{array}{l}\text { Bimolecular rate constant for binding of inactive form of cyclin } \\
\text { A/Cdk2 and active form of phosphatase } \operatorname{Cdc} 25 \mathrm{~Pa}\end{array}$ & $2 \mu \mathrm{M}^{-1} \mathrm{~h}^{-1}$ \\
\hline$k_{2 \text { Mai }}$ & $\begin{array}{l}\text { Rate constant for dissociation of complex between inactive form } \\
\text { of cyclin A/Cdk2 and active form of phosphatase Cdc } 25 \mathrm{~Pa}\end{array}$ & $1.2 \mathrm{~h}^{-1}$ \\
\hline$k_{\text {laa }}$ & $\begin{array}{l}\text { Apparent first-order rate constant for activation of cyclin } \\
\text { A/Cdk2 by phosphatase Cdc } 25 \mathrm{~Pa}\end{array}$ & $0.06 \mathrm{~h}^{-1}$ \\
\hline$k_{\text {2aа }}$ & $\begin{array}{l}\text { Apparent first-order rate constant for activation of phosphatase } \\
\qquad \mathrm{Cdc} 25 \mathrm{~Pa} \text { by cyclin } \mathrm{A} / \mathrm{Cdk} 2\end{array}$ & $0.3 \mathrm{~h}^{-1}$ \\
\hline$k_{\mathrm{c} 5}$ & Bimolecular rate constant for binding of cyclin $\mathrm{A} / \mathrm{Cdk} 2$ to $\mathrm{p} 27$ & $0.2 \mu \mathrm{M}^{-1} \mathrm{~h}^{-1}$ \\
\hline$k_{\mathrm{c} 6}$ & $\begin{array}{l}\text { Rate constant for dissociation of complex between cyclin } \\
\qquad \mathrm{A} / \mathrm{Cdk} 2 \text { and } \mathrm{p} 27\end{array}$ & $0.1 \mathrm{~h}^{-1}$ \\
\hline
\end{tabular}




\begin{tabular}{|c|c|c|}
\hline$k_{1 \text { Pai }}$ & $\begin{array}{l}\text { Bimolecular rate constant for binding of active form of cyclin } \\
\text { A/Cdk2 to inactive form of phosphatase Cdc25 Pai }\end{array}$ & $30 \mu \mathrm{M}^{-1} \mathrm{~h}^{-1}$ \\
\hline$k_{2 \text { Pai }}$ & $\begin{array}{l}\text { Rate constant for dissociation of complex between active form of } \\
\text { cyclin A/Cdk2 and inactive form of phosphatase Cdc25 Pai }\end{array}$ & $60 \mathrm{~h}^{-1}$ \\
\hline$k_{\text {lcdh1 }}$ & Bimolecular rate constant for binding of cyclin $\mathrm{A} / \mathrm{Cdk} 2$ to $\mathrm{Cdh} 1$ & $30 \mu \mathrm{M}^{-1} \mathrm{~h}^{-1}$ \\
\hline$k_{2 \mathrm{cdh} 1}$ & $\begin{array}{l}\text { Rate constant for dissociation of complex between cyclin } \\
\qquad \mathrm{A} / \mathrm{Cdk} 2 \text { and } \mathrm{Cdh} 1\end{array}$ & $20 \mathrm{~h}^{-1}$ \\
\hline$k_{\text {icdh } 1}$ & $\begin{array}{l}\text { Apparent first-order rate constant for inhibition by cyclin } \\
\qquad \mathrm{A} / \mathrm{Cdk} 2 \text { of } \mathrm{Cdh} 1\end{array}$ & $0.025 \mathrm{~h}^{-1}$ \\
\hline$k_{127 \mathrm{sk} 2}$ & Bimolecular rate constant for binding of $\mathrm{p} 27 \mathrm{p}$ to Skp2 & $4 \mu \mathrm{M}^{-1} \mathrm{~h}^{-1}$ \\
\hline$k_{227 \mathrm{sk} 2}$ & $\begin{array}{l}\text { Rate constant for dissociation of complex between } \mathrm{p} 27 \mathrm{p} \text { and } \\
\text { Skp2 }\end{array}$ & $2 \mathrm{~h}^{-1}$ \\
\hline$k_{\mathrm{da} 27 \mathrm{p}}$ & $\begin{array}{l}\text { Apparent first-order rate constant for degradation of p27 induced } \\
\text { by Skp2 }\end{array}$ & $0.1 \mathrm{~h}^{-1}$ \\
\hline$k_{\text {lbcdh1 }}$ & Bimolecular rate constant for binding of cyclin B to Cdh1 & $35 \mu \mathrm{M}^{-1} \mathrm{~h}^{-1}$ \\
\hline$k_{2 \mathrm{bcdh} 1}$ & $\begin{array}{l}\text { Rate constant for dissociation of complex between cyclin B and } \\
\qquad \text { Cdh1 }\end{array}$ & $5 \mathrm{~h}^{-1}$ \\
\hline$k_{3 \mathrm{~d}}$ & $\begin{array}{l}\text { Apparent first-order rate constant for degradation of cyclin B } \\
\text { induced by Cdh1 }\end{array}$ & $0.04 \mathrm{~h}^{-1}$ \\
\hline$P h o s 3_{\text {tot }}$ & $\begin{array}{l}\text { Total concentration of phosphatase Phos } 3 \text { leading to activation } \\
\text { of Cdh1 }\end{array}$ & $0.01 \mu \mathrm{M}$ \\
\hline$k_{\text {lacdh1 }}$ & $\begin{array}{l}\text { Bimolecular rate constant for binding of phosphatase Phos } 3 \text { to } \\
\text { inactive form of Cdh1 }\end{array}$ & $2 \mu \mathrm{M}^{-1} \mathrm{~h}^{-1}$ \\
\hline$k_{\text {2acdh1 }}$ & $\begin{array}{l}\text { Rate constant for dissociation of complex between phosphatase } \\
\text { Phos } 3 \text { and inactive form of Cdh1 }\end{array}$ & $1.25 \mathrm{~h}^{-1}$ \\
\hline$k_{\text {acdh1 }}$ & $\begin{array}{l}\text { Apparent first-order rate constant for activation, par } \\
\text { déphosphorylation, de Cdh1 }\end{array}$ & $0.04 \mathrm{~h}^{-1}$ \\
\hline$k_{\text {lcdhlb }}$ & Bimolecular rate constant for binding of cyclin $\mathrm{B} / \mathrm{Cdk} 1$ to $\mathrm{Cdh} 1$ & $30 \mu \mathrm{M}^{-1} \mathrm{~h}^{-1}$ \\
\hline$k_{2 \text { cdhlb }}$ & $\begin{array}{l}\text { Rate constant for dissociation of complex between cyclin } \\
\qquad \mathrm{B} / \mathrm{Cdk} 1 \text { and } \mathrm{Cdh} 1\end{array}$ & $20 \mathrm{~h}^{-1}$ \\
\hline$k_{\text {icdhlb }}$ & $\begin{array}{l}\text { Apparent first-order rate constant for inhibition of Cdh1 by } \\
\text { cyclin } \mathrm{B} / \mathrm{Cdk} 1\end{array}$ & $0.025 \mathrm{~h}^{-1}$ \\
\hline$k_{2 \mathrm{~d}}$ & $\begin{array}{l}\text { Apparent first-order rate constant for degradation of cyclin A } \\
\text { induced by } \mathrm{Cdc} 20 \text { protein }\end{array}$ & $0.4 \mathrm{~h}^{-1}$ \\
\hline$k_{\mathrm{dd} 3}$ & $\begin{array}{l}\text { Apparent first-order rate constant for non-specific degradation of } \\
\text { complex between cyclin A and Cdc20 }\end{array}$ & $0.001 \mathrm{~h}^{-1}$ \\
\hline$k_{1 \mathrm{Ma}}$ & $\begin{array}{l}\text { Bimolecular rate constant for binding of cyclin } \mathrm{A} / \mathrm{Cdk} 2 \text { to kinase } \\
\text { kin3 }\end{array}$ & $100 \mu \mathrm{M}^{-1} \mathrm{~h}^{-1}$ \\
\hline$k_{2 \mathrm{Ma}}$ & $\begin{array}{l}\text { Rate constant for dissociation of complex between cyclin } \\
\qquad \mathrm{A} / \mathrm{Cdk} 2 \text { and kinase kin } 3\end{array}$ & $10 \mathrm{~h}^{-1}$ \\
\hline$k_{\text {lia }}$ & $\begin{array}{l}\text { Apparent first-order rate constant for inactivation of cyclin } \\
\text { A/Cdk2 induced by kinase kin } 3\end{array}$ & $0.85 \mathrm{~h}^{-1}$ \\
\hline $\operatorname{kin} 3_{\text {tot }}$ & Total concentration of kinase kin3 & $0.01 \mu \mathrm{M}$ \\
\hline$k_{\text {lmawee }}$ & $\begin{array}{l}\text { Bimolecular rate constant for binding of cyclin } \mathrm{A} / \mathrm{Cdk} 2 \text { to kinase } \\
\text { Wee1 }\end{array}$ & $3 \mu \mathrm{M}^{-1} \mathrm{~h}^{-1}$ \\
\hline$k_{2 \text { mawee }}$ & $\begin{array}{l}\text { Rate constant for dissociation of complex between cyclin } \\
\text { A/Cdk2 and kinase Wee1 }\end{array}$ & $1 \mathrm{~h}^{-1}$ \\
\hline
\end{tabular}




\begin{tabular}{|c|c|c|}
\hline$v_{\text {scdh } 1}$ & Rate of synthesis of Cdh1 protein & $0.09 \mu \mathrm{Mh}^{-1}$ \\
\hline$v_{\mathrm{slp} 27}$ & Rate of synthesis of $\mathrm{p} 27$ protein & $0.1 \mu \mathrm{Mh}^{-1}$ \\
\hline$v_{\mathrm{s} 2 \mathrm{p} 27}$ & $\begin{array}{l}\text { Apparent first-order rate constant for p27 synthesis induced by } \\
\text { E2F }\end{array}$ & 0 \\
\hline \multicolumn{3}{|c|}{ Module Cyclin B/Cdk1 : G2 phase and G2/M transition } \\
\hline$k_{\mathrm{cb}}$ & Rate of synthesis of cyclin B & $0.12 \mu \mathrm{Mh}^{-1}$ \\
\hline$k_{\mathrm{com} 4}$ & Bimolecular rate constant for binding of cyclin B to kinase Cdk1 & $0.35 \mu \mathrm{M}^{-1} \mathrm{~h}^{-1}$ \\
\hline$k_{\text {decom4 }}$ & $\begin{array}{l}\text { Rate constant for dissociation of complex between cyclin B and } \\
\text { kinase Cdk1 }\end{array}$ & $0.1 \mathrm{~h}^{-1}$ \\
\hline$C d k 1_{\text {tot }}$ & Total concentration of kinase Cdk1 & $14 \mu \mathrm{M}$ \\
\hline$k_{\mathrm{ddCb}}$ & $\begin{array}{l}\text { Apparent first-order rate constant for non-specific degradation of } \\
\text { cyclin B }\end{array}$ & $0.12 \mathrm{~h}^{-1}$ \\
\hline$k_{\mathrm{dCbu}}$ & $\begin{array}{l}\text { Apparent first-order rate constant for degradation of } \\
\text { ubiquitinated form of cyclin B }\end{array}$ & $0.1 \mathrm{~h}^{-1}$ \\
\hline$k_{\mathrm{ddCbu}}$ & $\begin{array}{l}\text { Apparent first-order rate constant for non-specific degradation of } \\
\text { ubiquitinated form of cyclin B }\end{array}$ & $0.001 \mathrm{~h}^{-1}$ \\
\hline$k_{\mathrm{ddCdc} 20}$ & $\begin{array}{l}\text { Apparent first-order rate constant for non-specific degradation of } \\
\text { active form of Cdc } 20 \text { protein }\end{array}$ & $0.001 \mathrm{~h}^{-1}$ \\
\hline$k_{\mathrm{ddCdc} 20 \mathrm{i}}$ & $\begin{array}{l}\text { Apparent first-order rate constant for non-specific degradation of } \\
\text { inactive form of } \mathrm{Cdc} 20 \text { protein }\end{array}$ & $0.025 \mathrm{~h}^{-1}$ \\
\hline$k_{\mathrm{ddWeel}}$ & $\begin{array}{l}\text { Apparent first-order rate constant for non-specific degradation of } \\
\text { active form of kinase Wee1 }\end{array}$ & $0.01 \mathrm{~h}^{-1}$ \\
\hline$k_{\text {ddWeelp }}$ & $\begin{array}{c}\text { Apparent first-order rate constant for non-specific degradation of } \\
\text { inactive form of kinase Wee } 1\end{array}$ & $0.01 \mathrm{~h}^{-1}$ \\
\hline$k_{\mathrm{ddPb}}$ & $\begin{array}{l}\text { Apparent first-order rate constant for non-specific degradation of } \\
\text { active form of phosphatase } \operatorname{Cdc} 25 \mathrm{~Pb}\end{array}$ & $0.03 \mathrm{~h}^{-1}$ \\
\hline$k_{\mathrm{ddPbi}}$ & $\begin{array}{l}\text { Apparent first-order rate constant for non-specific degradation of } \\
\text { inactive form of phosphatase } \mathrm{Cdc} 25 \mathrm{Pbi}\end{array}$ & $0.015 \mathrm{~h}^{-1}$ \\
\hline$k_{\mathrm{scd} 20 \mathrm{i}}$ & Rate of synthesis of Cdc20 protein & $0.025 \mu \mathrm{Mh}^{-1}$ \\
\hline$k_{\mathrm{sPbi}}$ & Rate of synthesis of phosphatase $\mathrm{Cdc} 25 \mathrm{Pbi}$ & $0.01 \mu \mathrm{Mh}^{-1}$ \\
\hline$k_{\text {sweel } 1}$ & Rate of synthesis of kinase Weel & $0.03 \mu \mathrm{Mh}^{-1}$ \\
\hline$k_{1 \mathrm{Mbi}}$ & $\begin{array}{l}\text { Bimolecular rate constant for binding of inactive form of cyclin } \\
\text { B/Cdk1 to active form of phosphatase } \mathrm{Cdc} 25 \mathrm{~Pb}\end{array}$ & $5.75 \mu \mathrm{M}^{-1} \mathrm{~h}^{-1}$ \\
\hline$k_{2 \mathrm{Mbi}}$ & $\begin{array}{l}\text { Rate constant for dissociation of complex between inactive form } \\
\text { of cyclin } \mathrm{B} / \mathrm{Cdk} 1 \text { and active form of phosphatase } \mathrm{Cdc} 25 \mathrm{~Pb}\end{array}$ & $4 \mathrm{~h}^{-1}$ \\
\hline$k_{1 \mathrm{Mb}}$ & $\begin{array}{l}\text { Bimolecular rate constant for binding of cyclin } \mathrm{B} / \mathrm{Cdk} 1 \text { to kinase } \\
\qquad \text { Weel }\end{array}$ & $18 \mu \mathrm{M}^{-1} \mathrm{~h}^{-1}$ \\
\hline$k_{2 \mathrm{Mb}}$ & $\begin{array}{l}\text { Rate constant for dissociation of complex between cyclin } \\
\text { B/Cdk1 and kinase Weel }\end{array}$ & $1 \mathrm{~h}^{-1}$ \\
\hline$k_{\text {la }}$ & $\begin{array}{l}\text { Apparent first-order rate constant for activation of cyclin B/Cdk1 } \\
\text { induced by phosphatase Cdc25 Pb }\end{array}$ & $0.125 \mathrm{~h}^{-1}$ \\
\hline$k_{2 \mathrm{a}}$ & $\begin{array}{l}\text { Apparent first-order rate constant for activation of phosphatase } \\
\text { Cdc25 } \mathrm{Pb} \text { induced by cyclin } \mathrm{B} / \mathrm{Cdk} 1\end{array}$ & $0.05 \mathrm{~h}^{-1}$ \\
\hline$k_{3 \mathrm{a}}$ & $\begin{array}{l}\text { Apparent first-order rate constant for activation of } \mathrm{Cdc} 20 \text { protein } \\
\text { induced by cyclin } \mathrm{B} / \mathrm{Cdk} 1\end{array}$ & $0.04 \mathrm{~h}^{-1}$ \\
\hline$k_{1 \mathrm{Pbi}}$ & Bimolecular rate constant for binding of active form of cyclin & $4 \mu \mathrm{M}^{-1} \mathrm{~h}^{-1}$ \\
\hline
\end{tabular}




\begin{tabular}{|c|c|c|}
\hline & $\mathrm{B} / \mathrm{Cdk} 1$ to inactive form of phosphatase $\mathrm{Cdc} 25 \mathrm{Pbi}$ & \\
\hline$k_{2 \mathrm{Pbi}}$ & $\begin{array}{l}\text { Rate constant for dissociation of complex between active form of } \\
\text { cyclin B/Cdk1 and inactive form of phosphatase } \mathrm{Cdc} 25 \mathrm{Pbi}\end{array}$ & $3 \mathrm{~h}^{-1}$ \\
\hline$k_{1 \mathrm{cdc} 20 \mathrm{i}}$ & Bimolecular rate constant for binding of cyclin $\mathrm{B} / \mathrm{Cdk} 1$ to $\mathrm{Cdc} 20$ & $5 \mu \mathrm{M}^{-1} \mathrm{~h}^{-1}$ \\
\hline$k_{2 \mathrm{cdc} 20 \mathrm{i}}$ & $\begin{array}{l}\text { Rate constant for dissociation of complex between cyclin } \\
\qquad \mathrm{B} / \mathrm{Cdk} 1 \text { and } \mathrm{Cdc} 20\end{array}$ & $4.5 \mathrm{~h}^{-1}$ \\
\hline$k_{1 \mathrm{Wp}_{\mathrm{p}}}$ & $\begin{array}{l}\text { Bimolecular rate constant for binding of kinase Weel to } \\
\text { phosphatase Phos } 1\end{array}$ & $2 \mu \mathrm{M}^{-1} \mathrm{~h}^{-1}$ \\
\hline$k_{2 \mathrm{Wp}}$ & $\begin{array}{l}\text { Rate constant for dissociation of complex between kinase Wee1 } \\
\text { and phosphatase Phos } 1\end{array}$ & $1.25 \mathrm{~h}^{-1}$ \\
\hline$k_{\mathrm{c} 7}$ & Bimolecular rate constant for binding of cyclin $\mathrm{B} / \mathrm{Cdk} 1$ to $\mathrm{p} 27$ & $0.05 \mu \mathrm{M}^{-1} \mathrm{~h}^{-1}$ \\
\hline$k_{\mathrm{c} 8}$ & $\begin{array}{l}\text { Rate constant for dissociation of complex between cyclin } \\
\qquad \mathrm{B} / \mathrm{Cdk} 1 \text { and } \mathrm{p} 27\end{array}$ & $0.1 \mathrm{~h}^{-1}$ \\
\hline$k_{1 \mathrm{bcd} 20}$ & $\begin{array}{l}\text { Bimolecular rate constant for binding of cyclin B to Cdc20 } \\
\text { protein }\end{array}$ & $40 \mu \mathrm{M}^{-1} \mathrm{~h}^{-1}$ \\
\hline$k_{2 \mathrm{bcdc} 20}$ & $\begin{array}{l}\text { Rate constant for dissociation of complex between cyclin B and } \\
\qquad \text { Cdc20 }\end{array}$ & $10 \mathrm{~h}^{-1}$ \\
\hline$k_{1 \mathrm{~d}}$ & $\begin{array}{l}\text { Apparent first-order rate constant for degradation of cyclin B } \\
\text { induced by Cdc20 }\end{array}$ & $0.125 \mathrm{~h}^{-1}$ \\
\hline$k_{1 \mathrm{CP} 2}$ & $\begin{array}{l}\text { Bimolecular rate constant for binding of phosphatase Phos } 2 \text { to } \\
\qquad \text { Cdc20 }\end{array}$ & $20 \mu \mathrm{M}^{-1} \mathrm{~h}^{-1}$ \\
\hline$k_{2 \mathrm{CP} 2}$ & $\begin{array}{l}\text { Rate constant for dissociation of complex between phosphatase } \\
\qquad \text { Phos } 2 \text { and Cdc20 }\end{array}$ & $15 \mathrm{~h}^{-1}$ \\
\hline$k_{1120}$ & $\begin{array}{l}\text { Apparent first-order rate constant for inactivation of Cdc20 } \\
\text { induced by phosphatase Phos } 2\end{array}$ & $0.01 \mathrm{~h}^{-1}$ \\
\hline Phos $1_{\text {tot }}$ & $\begin{array}{c}\text { Total concentration of phosphatase Phosl leading to activation } \\
\text { of kinase Wee1 }\end{array}$ & $0.01 \mu \mathrm{M}$ \\
\hline$P h o s 2_{\text {tot }}$ & $\begin{array}{l}\text { Total concentration of phosphatase Phos } 2 \text { leading to inactivation } \\
\text { of } \operatorname{Cdc} 20\end{array}$ & $0.01 \mu \mathrm{M}$ \\
\hline$k_{\mathrm{dd} 2}$ & $\begin{array}{l}\text { Apparent first-order rate constant for non-specific degradation of } \\
\text { complex between Cdc20 and cyclin B }\end{array}$ & $0.01 \mathrm{~h}^{-1}$ \\
\hline$k_{\text {law }}$ & $\begin{array}{c}\text { Apparent first-order rate constant for activation of kinase Wee1 } \\
\text { induced by phosphatase Phos } 1\end{array}$ & $0.04 \mathrm{~h}^{-1}$ \\
\hline$k_{1 \mathrm{i}}$ & $\begin{array}{l}\text { Apparent first-order rate constant for mutual inactivation of } \\
\text { cyclin B/Cdk1 and kinase Wee1 }\end{array}$ & $0.01 \mathrm{~h}^{-1}$ \\
\hline
\end{tabular}

